\section{Intersections}

Canadian Journal of Music

Revue canadienne de musique
Intersections CANADIAN JOURAL OF MUSIC
REVUE CANADIENEE DE MUSIOUH

\title{
L'impact des politiques institutionnelles sur la création d'opéra au Canada entre 1980 et 2003 : Les cas de Montréal et Toronto
}

\section{Sophie Bisson}

Volume 28, numéro 1, 2007

URI : https://id.erudit.org/iderudit/019292ar

DOI : https://doi.org/10.7202/019292ar

Aller au sommaire du numéro

\section{Éditeur(s)}

Canadian University Music Society / Société de musique des universités canadiennes

ISSN

1911-0146 (imprimé)

1918-512X (numérique)

Découvrir la revue

Citer cet article

Bisson, S. (2007). L'impact des politiques institutionnelles sur la création d’opéra au Canada entre 1980 et 2003 : Les cas de Montréal et Toronto.

Intersections, 28(1), 78-124. https://doi.org/10.7202/019292ar
Résumé de l'article

L'analyse des différents programmes d'aide offerts par les conseils des arts canadiens révèle que l'aide financière gouvernementale est insuffisante pour permettre la création régulière d'oeuvres opératiques. L'étude du fonctionnement des organismes professionnels qui bénéficient de ces programmes d'aide (incluant les ateliers professionnels et universitaires), ainsi que l'étude des mécanismes entourant la création d'un opéra (de sa commande à sa réalisation), démontre que l'essentiel des fonds contribue au fonctionnement des différents organismes lyriques du pays et non à la création. Pour permettre la création d'opéra au Canada, les créateurs doivent emprunter le chemin de la compagnie lyrique et non de la maison d'opéra.
Tous droits réservés (C) Canadian University Music Society / Société de musique des universités canadiennes, 2007
Ce document est protégé par la loi sur le droit d'auteur. L'utilisation des services d'Érudit (y compris la reproduction) est assujettie à sa politique d'utilisation que vous pouvez consulter en ligne.

https://apropos.erudit.org/fr/usagers/politique-dutilisation/ 
L'IMPACT DES POLITIQUES INSTITUTIONNELLES

SUR LA CRÉATION D'OPÉRA AU CANADA

ENTRE 1980 ET 2003

Les CAS DE Montréal et Toronto ${ }^{1}$

Sophie Bisson

Depuis plus de quatre siècles, les compositeurs, les librettistes, les metteurs en scène, les chanteurs, les mécènes, le public ainsi que les représentants de la noblesse ou de l'État, selon les époques, se croisent dans les couloirs de l’opéra. Le genre a considérablement évolué au fil du temps, mais, jusqu’à un certain point, il nous semble que le milieu de l'opéra (de part et d'autre de la scène) a conservé de nombreuses caractéristiques héritées du XIX ${ }^{\mathrm{e}}$ siècle. Dans ce cadre, nous nous sommes demandés si les politiques institutionnelles culturelles et gouvernementales contemporaines ont tendance à modifier ce milieu si stable et, si oui, jusquà quel point. Ce questionnement est donc à l'origine de cette étude évaluant les mécanismes administratifs et leurs effets sur la musique, ouvrant ainsi la porte à une meilleure compréhension de leurs conséquences sur la création d'opéra au Canada.

Au cours des vingt dernières années, le regain de vitalité de l’opéra en occident s'est caractérisé par plusieurs facteurs. D’une part, il a acquis une notoriété auprès du grand public grâce à la télévision par l'intermédiaire de la publicité (Dunkin Donuts, Lexus, Nissan, Nike, Pepsi et Visa) et il est aussi présent au cinéma par l'entremise des trames sonores de films (Diva, Fatal Attraction, The Godfather III, Philadelphia et Pretty Woman). D’autre part, le développement de la technologie, parfois perçu comme une menace aux pratiques esthétiques établies depuis deux siècles, permet aujourd'hui à l'opéra de rejoindre des millions de téléspectateurs par l'entremise de supports tels que la bande vidéo et le disque vidéo digital (DVD). Larrivée des surtitres compte aussi parmi les instruments technologiques qui facilitent l'adhésion du public à l'opéra. Maintes collaborations entre artistes de médium différents ont aussi vu le jour : citons l'arrivée de metteurs en scène du théâtre ou du cinéma à l’opéra qui a donné, par exemple, la mise en scène des opéras Erwartung de Schoenberg et Le Château de Barbe Bleue de Bartók par Robert Lepage ${ }^{2}$; la mise en scène de Salomé de Strauss par le cinéaste Atom Egoyan ${ }^{3}$; et les albums Pavarotti \& friends. Finalement, létendue

1 Le présent travail propose une synthèse d'un mémoire de maîtrise portant le même titre.

2 Présentée pour la première fois au Canada à Toronto, le 22 janvier 1993, par la Canadian Opera Company.

3 Présentée pour la première fois au Canada à Toronto, en 1996, par la Canadian Opera Company. Bien que d'autres metteurs en scène de théâtre ont travaillé à l'opéra, notamment Jean Gascon et Albert 
de l'intérêt pour le genre est aussi mise en évidence par la publication de multiples revues destinées au public (Opera News, Opera America et Opera Canada) ou encore de périodiques à caractère plus érudit tel que The Opera Quarterly et Avant-Scène opéra dont le nombre d'abonnés se maintient ou augmente.

L'engouement que semble connaître à nouveau le genre opératique se traduit aussi par l'augmentation significative de l'aide financière qu'accordent les différents ordres de gouvernement et par l'accroissement des ventes de billets. De plus, le conservatisme qui caractérise l'opéra semble laisser la place à une plus grande ouverture, et plusieurs compositeurs contemporains se réapproprient les différentes formes que peut prendre lart lyrique. Cette revitalisation se manifeste par le développement d'un répertoire contemporain qui ne trouve peut-être pas place dans toutes les maisons d'opéra, mais qui est soutenu par certaines des plus grandes institutions du monde que l'on trouve en Finlande, aux États-Unis (San Francisco, Houston), au Japon, en Belgique (Bruxelles) et en Australie (Sydney).

Le Canada ne fait pas exception à ce nouveau dynamisme de l'opéra et les signes en sont tangibles : la construction d'une nouvelle salle de spectacle dédiée à l'opéra et au ballet à Toronto, le Four Seasons Centre for the Performing Arts 4 ; les succès d'assistance des maisons d'opéra; la quantité de création de nouveaux opéras; et la relative abondance de commandes, notamment dans les grands centres comme Montréal, Toronto et Vancouver. De plus, le Conseil des Arts du Canada, en collaboration avec Opera.ca, a créé, en 2001, un fonds d'opéra soutenant le Programme de création dopéras canadiens et a promis d'y injecter 2,5 millions de dollars en 5 ans (CAC 2004.1). Ces sommes témoignent non seulement de l'engagement du Conseil des Arts du Canada envers la création d’opéra au Canada, mais sous-tendent aussi une notion de "nécessité » car, inévitablement, les investissements de cette envergure témoignent de la valorisation de ce répertoire pour la société.

Plusieurs travaux ont été consacrés aux politiques culturelles en général, mais le sujet n’a pas encore été vraiment abordé lorsqu'il s'agit de rendre compte directement de l'art ou de l'opéra. Parmi les ouvrages récents qui touchent à des thèmes connexes à notre recherche, citons particulièrement: The Operatic State: Cultural Policy and the Opera House (Bereson 2002), une étude dense portant sur les aspects culturels, financiers et politiques de lopéra et des maisons d’opéra de l'Amérique, l'Angleterre, l'Italie, la France, la Russie et l'Australie; Composer un opéra aujourd'hui (Ramaut-Chevassus 2003), un ouvrage détaillant plusieurs

\footnotetext{
Millaire à l'Opéra de Montréal, ils n’ont pas tous la même influence sur le développement scénographique en cette fin de vingtième siècle qu'un Robert Lepage.

4 Inauguré en juin 2006, le Four Seasons Centre for the Performing Arts, est inspiré des modèles européens. Il a une capacité de 2000 place et possède une adresse prestigieuse, aux coins des rues Queen et University. La Canadian Opera Company y a présenté la première canadienne (par une maison d’opéra canadienne) du chef-d’euvre de Richard Wagner, Der Ring des Nibelung, à partir de septembre 2006. La construction fut rendue possible en grande partie grâce aux dons du gouvernement de l'Ontario (soit 41 millions de dollars, incluant le terrain évalué à 31 millions de dollars ainsi qu'un don de 10 millions de dollars), du gouvernement du Canada (25 millions de dollars) et du Four Seasons Hotels (20 millions de dollars), dont le centre a pris le nom. Une multitude de donateurs, dont les dons varient entre 1 million de dollars et 22,6 millions de dollars, sont remerciés sur le site Internet du Four Seasons Centre.
} 
aspects de la création lyrique actuelle, son développement non conformiste, avec une interrogation sur son futur; Opera and Politics: From Monteverdi to Henze (Bokina 1997), qui explore les liens entre les opéras et les idées politiques et culturelles de leur époque, ainsi que les relations changeantes entre les compositeurs, l'art, la politique et la société. L'auteur se sert de quelques œuvres du répertoire contemporain du début du siècle pour établir son argumentation, mais il se réfère principalement au canon traditionnel. Notons aussi une thèse de Doctorat récente intitulé Who Will Buy?: An Examination of Historical and Contemporary Practices of Operatic Patronage in Twentieth-Century America (Jenkins 2003), qui aborde des thèmes similaires à ceux traités ici, mais en se concentrant sur les États-Unis.

Quant au sujet précis de l'opéra contemporain au Canada, la littérature est encore moins abondante. Lapport de cette recherche constitue donc une ouverture vers un champ nouveau ou peu exploré. Par la réunion de données factuelles nous visons à élargir la compréhension des liens, parfois facilement perceptibles, bien qu'ils recouvrent des mécanismes complexes, entre les bailleurs de fonds, les conseils des arts, les compositeurs, les organismes lyriques, les maisons d'opéra et le public ${ }^{5}$.

Dans le cadre d'une étude dirigée sur l'opéra contemporain, réalisée dans le cadre détudes de baccalauréat, nous avons effectué un recensement d'œuvres opératiques canadiennes du $\mathrm{xx}^{\mathrm{e}}$ siècle. Le répertoire est intitulé "TwentiethCentury Canadian Operas Written by Canadian Born or Naturalised Citizens and Landed Immigrants ${ }^{6}$ (Bisson 1998). Ce recensement, mis à jour en 2004, indique que le répertoire d'opéras canadiens $\mathrm{du} \mathrm{xx}^{\mathrm{e}}$ siècle est constitué d'au moins 286 œuvres. L'étude confirme le dynamisme en matière de composition d’opéra au Canada et cela, tout particulièrement à partir des années 1960. Mentionnons toutefois que les œuvres recensées nont pas toutes été créées. De ce répertoire, seulement sept opéras composés entre 1900 et 1950 n’ont pas été créés, tandis que c'est le cas d'au moins une dizaine d'œuvres pour chaque décennie suivante. Cependant, il est difficile de déterminer le nombre exact d'œuvres créées au $\mathrm{xx}^{\mathrm{e}}$ siècle puisque plusieurs d'entre elles ont reçu une première " non officielle », c'est-à-dire qu'elle prenait place dans une institution d'enseignement où l'entrée est gratuite et où l'événement ne retient pas nécessairement l'attention de la presse, ou parce que les opéras étaient donnés en lecture publique par des organismes tels que COMUS Canada. Si l'on ne considère pas ces présentations comme des premières " officielles », le nombre de créations diminue alors considérablement. Pourtant, les institutions nécessaires à la création de ces opéras existent, et ce, depuis le début du xx $x^{\mathrm{e}}$ siècle. En effet, entre 1917 et 1980, une

5 Dans ce texte, une maison d'opéra fait référence à des institutions comme la Canadian Opera Company, l'Opéra de Montréal et la Calgary Opera Association, disposant d'un important budget et dont le répertoire n'est constitué que d'opéra, habituellement traditionnel, mais produisant et créant parfois de nouvelles œuvres. Un organisme lyrique renvoie aux plus petites compagnies dont le mandat est habituellement consacré à la création.

6 Pour 1900 à 1959, les œuvres répertoriées comprennent 29 œuvres composées, dont 11 en français; pour 1960 à 1979, 75 œuvres composées, dont 3 en français; pour 1980 à 1999, 95 œuvres composées, dont 22 en français. 
douzaine d'associations opératiques se sont formées à Toronto et une trentaine à Montréal (Cooper 1985).

Cette recherche a aussi révélé, sans surprise, que la création d’opéra se concentre dans deux grandes villes du Canada, à savoir Montréal et Toronto. C'est dans cette optique que cette étude se concentre sur l'activité musicale de ces deux centres urbains qui, par conséquent, nous apparaissent bien refléter l'ensemble de la discipline au Canada. Pour les besoins de la démonstration néanmoins, nous pourrons citer des données empruntées à d’autres villes canadiennes, notamment Calgary et Vancouver, dont l'opéra occupe une place croissante dans le panorama musical national ${ }^{7}$.

Avec des opéras et un répertoire opératique canadien relativement vaste, du moins en théorie, la question se pose de savoir pourquoi tant d’ouvres nont pas reçu une première formelle. La réponse comporte de multiples facettes. Parmi les principales, retenons le faible intérêt du public pour ce répertoire, la maigre rentabilité des œuvres ainsi que l'importance des coûts ou le faible intérêt témoigné par les maisons d’opéra (compte tenu de la difficulté à financer ces nouvelles œuvres).

Puisque l'opéra est un genre dispendieux, sa création est souvent étroitement liée à une subvention et s'accompagne fréquemment de restrictions, qui touchent par exemple à la durée de l’ouvre, le nombre d’actes qui la composent et la quantité de musiciens et de chanteurs mis à contribution. De plus, les maisons d'opéra assurent rarement une première diffusion d'une ouvre nouvelle et invoquent souvent l'une ou l'autre des raisons mentionnées précédemment pour justifier leur refus de s'aventurer dans le domaine de la création. Il est donc juste de s'interroger sur la pertinence de soutenir l'écriture d’œuvres opératiques puisque celles-ci ne sont pas toutes créées en public ou ne sont jouées qu'une seule fois. De plus, l'encadrement institutionnel imposé par les organismes subventionnaires, habituellement gouvernementaux, fausse peut-être aussi l'évolution naturelle du genre de l'opéra. Cela dit, cette dernière pratique n'est pas nouvelle, mais il sera néanmoins intéressant d’en évaluer les conséquences.

Lartiste contemporain aurait tendance à écrire et à créer pour des milieux sans lien nécessaire avec son propre cadre politique et identitaire. On note donc une forme d'indépendance de la création par rapport à l'environnement social et, par conséquent, de l'État qui gère cet environnement. Mais si l'on tient compte des modalités qui entourent la création d’opéra, aujourd'hui intimement liées au soutien de l'État aux yeux de plus d'un acteur dans le milieu, quels sont les principaux mécanismes qui régissent la commande et la création d'un opéra? En tenant compte de la persistance du soutien financier de l'État, que ce soit par l'intermédiaire de la noblesse ou par un système démocratique moderne, la création d'opéra peut-elle exister sans cette aide? En définitive, l'aide gouvernementale est-elle contraignante? Est-ce que la création d'opéra ne devrait pas se tourner vers d'autres sources d'appui pour gagner en indépendance par rapport au circuit étatique mis en place depuis une trentaine d'années? Finalement, si

7 Afin de respecter les limites imparties à cet article, plusieurs démonstrations touchant d'autres villes canadiennes ont dû être retranchées. 
l'on tient compte de l'extraordinaire amalgame des peuples du Canada,la création d'un opéra joue-t-elle vraiment un rôle fondamental pour l'affirmation d'une identité artistique canadienne?

Nous supposons que certaines réponses à nos questions se trouvent dans les politiques de nos institutions, tant gouvernementales quartistiques, ainsi que dans la vision des créateurs et de tous les acteurs, qu'ils soient artistes professionnels, enseignants ou futurs chanteurs d'opéra ${ }^{8}$. Dans le cadre de cet article, les donnés factuelles réunies permettront une analyse dont lobjectif est de comprendre les mécanismes de fonctionnement du milieu de l’opéra et ainsi éclairer les mécanismes d'influence sur la création d'œuvres destinées à l'opéra ${ }^{9}$.

Le présent article est structuré en deux parties. La première, intitulée « Les grands programmes d'aide à l'opéra au Canada ", a pour objectif de présenter les différents conseils des arts tout en s'attardant plus particulièrement à leur action auprès des maisons d’opéra au Canada; de décrire en détail les programmes d'aide offerts; de présenter les organismes qui bénéficient de cette aide; et d'aborder le sujet des " ateliers » (programmes de formation universitaires rattachés à une maison d’opéra) ainsi que des programmes de développement de l'auditoire. Cette partie vise à fournir une meilleure compréhension des mécanismes qui régissent les relations entre les maisons d’opéra, la place qui y est accordée pour la création et l'appui gouvernemental.

La deuxième partie, "Le contexte actuel de la création d'opéra au Canada », a pour objectif de présenter les éléments entourant et régissant la commande d'un opéra; d'explorer les diverses influences du milieu culturel sur la création; et de se pencher sur la raison dêtre de l'opéra contemporain au Canada. Ces sections proposeront une synthèse des propos recueillis auprès des compositeurs, interprètes et directeurs artistiques.

\section{LES GRANDS PROGRAMMES D'AIDE À L'OPÉRA AU CANADA PRÉSENTATION GÉNÉRALE}

\section{Les programmes fédéraux}

À l'échelle pancanadienne, nous retrouvons le Conseil des Arts du Canada (CAC). Lorganisme autonome rend compte de ses activités au Parlement par l'intermédiaire du ministre du Patrimoine canadien (le CAC dépend avant tout de l’enveloppe financière que lui vote le Parlement chaque année). Pour l’année

8 Les ateliers universitaires ne possèdent pas le statut d’organismes «professionnels ", mais nous évaluerons tout de même les principaux, car l'investissement dans léducation semble entraîner des résultats positifs quant à la formation de la relève et du développement du goût pour la création.

9 Cette étude ne prétend pas définir les genres qui pourraient être considérés comme des successeurs de l'opéra traditionnel. Cependant, puisque la majorité des organismes et des compagnies lyriques étudiés ici se disent producteurs d'opéra ou de théâtre musical et reçoivent une aide financière en ce sens, les paramètres musicaux de l'organisation formelle ne constitueront pas des critères d'exclusion. Lévolution de la tradition savante vers les œuvres de théâtre musical et les opéras à voix et instrumentations réduites nous obligent à élargir la définition d’opéra contemporain aux types d’œuvres que produisent les nouvelles compagnies de créations. Par conséquent, seuls les genres de la comédie musicale, du musical theatre et de l'opéra rock seront exclus de notre analyse. 
2002-2003, le secteur musique a reçu 7,6 millions des 41 millions de dollars attribués aux arts pour la province de Québec (CAC 2003.1) et 10,1 millions des 42,9 millions pour l'Ontario (CAC 2003.2). Les sommes totales accordées aux programmes d'aide à l'opéra sont d’environ 1 million de dollars pour le Québec (CAC 2003.3) et de 2,7 millions pour l'Ontario (CAC 2003.4). La contribution du CAC à l'opéra ou au théâtre musical se fait par l'entremise de trois programmes d'aide, soit Aide annuelle ou pluriannuelle, Aide de projet ainsi que Résidences et commandes de compositions canadiennes ${ }^{10}$.

\section{Les programmes provinciaux}

$\mathrm{Au}$ provincial, nous retrouvons le Conseil des arts et des lettres du Québec (CALQ) et le Conseil des arts de l'Ontario (CAO). Le CALQ reçoit ses crédits du ministère de la Culture, et, si l'organisme est indépendant, ses orientations doivent tout de même être approuvées par le ministre. Sur un budget total d'environ 13 millions de dollars pour la musique ${ }^{11}$, le CALQ a accordé environ 2 millions à des organismes producteurs d’opéras pour l'année 2002-2003 (CALQ 2003.1). Parmi les organismes étudiés, l'Opéra de Montréal, Chants Libres et l'Atelier lyrique de l'Opéra de Montréal ont reçu des subventions dont les montants ont été semblables pour les cinq dernières périodes d'attribution, soit respectivement une moyenne d'environ 700000 \$ pour l'Opéra de Montréal (OdM), entre 90000 \$ et 132000 \$ pour Chants Libres (CL) et entre 94000 \$ et 144000 \$ pour l'Atelier lyrique de l'Opéra de Montréal (CALQ 2003.2) ${ }^{12}$. Les subventions sont octroyées à l'opéra par le biais des programmes de subvention aux organismes de production (Soutien aux projets et soutien au fonctionnement). Les programmes Recherche et création ainsi que Commandes d'œuvres et résidences subventionnent directement l'artiste (le compositeur).

Le Conseil des arts de l'Ontario (CAO) est un organisme autonome qui relève du ministère du Tourisme, de la Culture et des Loisirs. En 2003-2004, il a octroyé des subventions totalisant 29,3 millions de dollars à 1378 artistes et 867 organismes (CAO 2004). Pour la saison 2002-2003, le budget du secteur musique représentait environ 4,3 millions de dollars, duquel il a accordé 1,24 million à des organismes producteurs d'opéras (CAO 2003). Au cours de leur existence, la majorité des organismes de Toronto étudiés ici ont reçu des sommes importantes du CAO. Par exemple, Autumn Leaf Performance (ALP) a reçu des sommes annuelles de 15000 \$̀̀ 18000 \$ de 1998 à $2002^{13}$. Pour la même période, les or-

10 Dans les parties suivantes, chacune des formes d'aide à la musique sera nommée en relation au conseil auquel elle se rattache. Cependant, même si plusieurs d'entre elles visent des activités ou des initiatives diverses susceptibles d'aider l'opéra, seulement celles qui y contribuent directement seront analysées.

11 Noter que ce total inclut seulement les catégories " Musique classique " et "Fonctionnement ", car celles-ci englobent la majorité de sommes reçues par les producteurs d'opéras.

12 Pour une synthèse de l'aide accordée aux principaux organismes de cette étude, voir l'Annexe 1.

13 Pourtant bien établi depuis le début des années 1990, et ayant tissé des liens avec d’autres organismes tels que l'Opéra de Montréal et le Centre des arts de Banff pour la tournée de l'opéra Kopernikus en 2000, Autumn Leaf Performance a cessé d'exister en 2005. L'organisme, qui produisait du théâtre musical et de l'opéra très avant-gardiste en utilisant de nouvelles technologies et des locaux inusités, s'est retrouvé en difficulté financière. Ne répondant plus aux critères de santé financière suffisante, ALP s'est 
ganismes Queen of Puddings (QP) et Tapestry New Opera Works (TNOW) ont reçu une aide qui sest accrue, soit respectivement de 13500 \$ en 1998 à 38000 \$ en 2002 pour Queen of Puddings et de $33300 \$$ à $70000 \$$ pour Tapestry New Opera Works. Le Conseil gère deux programmes d'aide en rapport avec notre étude, soit Commande d'œuvres musicales et Compagnies d’opéra et de théâtre musical.

\section{Les programmes municipaux}

Les villes de Montréal et de Toronto possèdent aussi leur propre conseil des arts. Disposant d'un budget du même ordre (entre 8 et 9 millions de dollars), les conseils ne gèrent pas de programme spécifique à l'opéra, mais subventionnent annuellement les compagnies lyriques importantes de leur ville.

En 2003, Le Conseil des arts de Montréal (CAM) disposait d'un budget de 9 millions de dollars, réparti entre plus de 240 organismes culturels, dont une cinquantaine en musique. Le dernier rapport annuel disponible nous apprend qu'en 2002, le secteur de la musique a reçu 1998400 \$. De ce budget, environ $30000 \$$ ont été accordés à Chants Libres et 150000 \$ à l'Opéra de Montréal. Ces deux organismes bénéficient de l'appui du CAM depuis de nombreuses années et ont reçu des montants similaires à ceux mentionnés pour chaque année d'attribution depuis 1998. Le CAM offre le Programme général de subventions aux organismes artistiques ainsi que le programme de tournée Jouer dans l'île.

Le Conseil des arts de Toronto (CAT) reçoit son budget, soit environ 8 millions de dollars, de la Ville de Toronto. Pour les saisons précédentes, environ 1,56 million de dollars de ce budget ont été attribués au secteur de la musique et environ 126000 \$ par année ont été divisés entre les compagnies productrices d’opéras Autumn Leaf Performance, Queen of Puddings et Tapestry New Opera Works (CAT 1999-2003). Les subventions sont versées par le biais du Music Program pour les organismes et par le Music Creators and Composers Program pour les artistes professionnels. Il est à noter que le CAT subventionne indirectement la Canadian Opera Company (COC). En effet, c'est le Département des affaires culturelles de la ville de Toronto qui gère le portefeuille des subventions attribuées aux institutions dites de grande importance. Un budget de 3,2 millions de dollars sert les divisions culturelles Arts Services, Museums and Heritage Services, ainsi que Preservation Services et permet de soutenir, entre autres, la Galerie d'art de l'Ontario, le Ballet national du Canada, l'École nationale de ballet du Canada, l'Orchestre symphonique de Toronto et la Canadian Opera Company. La COC a reçu 854970 \$ pour les saisons 2000 et 2001 et 861 $162 \$$ pour les saisons 2002 et 2003 (CAT / City 1999-2003).

\section{OPERA.CA}

Il existe aussi un organisme non gouvernemental, Opera.ca, qui subventionne l'opéra à l'échelle nationale par le Programme de création d’opéras canadiens.

vu dans l'obligation de cesser ses activités. Le cas de Autumn Leaf Performance nous permet de démontrer concrètement que même un organisme lyrique dit à succès n'est pas à l'abri de tout souci et que les appréhensions des dirigeants de divers organismes envers la création sont, jusquà un point, justifiées. 
Intégré à Opera America en 2000, l'organisme vise plusieurs objectifs, dont l'accès aux subventions des conseils des arts, une structure formelle lui permettant de grandir et d’obtenir une certaine indépendance par rapport à Opera America et, surtout, de devenir le principal organisme représentatif du milieu de l'opéra au Canada ${ }^{14}$.

Le partenariat avec Opera America est crucial, car l'organisme assume tous les coûts administratifs d'Opera.ca, permettant ainsi à ce dernier d'injecter toutes les sommes reçues directement à la création d’opéra. Opera.ca est un cas particulier parmi les organismes évalués dans ce travail, car il ne reçoit pas d'aide de fonctionnement des différents conseils, et le salaire des employés est couvert par les dons, par des subventions à cet effet et par les cotisations d’adhésion ${ }^{15}$.

Les sommes reçues proviennent du Conseil des Arts du Canada qui, en 2002, a créé un fonds dopéra et s'est engagé à y injecter 2,5 millions de dollars en cinq ans. Les subventions accordées par Opera.ca se font par l'entremise du Programme de création d’opéras canadiens. De plus, le Canadian Opera Fund, qui opère de concert avec le US Opera Fund d'Opera America, a pour objectif à long terme de créer un fonds de 30 millions de dollars en capital afin de soutenir et d'encourager la création, le développement et la production d'opéra et de théâtre musical en Amérique du Nord ${ }^{16}$.

\section{LES PROGRAMMES SPÉCIFIQUES D’AIDE ${ }^{17}$}

\section{Fonctionnement général}

Chacun des conseils des arts a pour objectif de favoriser et de promouvoir l'étude, la recherche, la création et la diffusion des arts, ainsi que d'aider les artistes et les organismes culturels. Les différents jurys sont composés d’au moins trois personnes, des pairs habituellement choisis par le directeur du programme à partir d'une liste approuvée par le conseil d'administration ${ }^{18}$. Les membres des jurys sont sélectionnés en fonction de leurs connaissances spécialisées en opéra, en théâtre musical et dans divers domaines artistiques connexes. Dans la mesure du possible, la composition des jurys doit refléter les diversités régionales, culturelles, ethnoculturelles, artistiques et linguistiques qui caractérisent le Canada. Il n'existe pas de jury permanent, et les comités de sélection sont renouvelés à chaque cycle de subvention. Les conseils dadministration prennent les décisions finales quant à l'attribution des bourses et des subventions ${ }^{19}$.

14 Information recueillie auprès de Micheline Mc Kay, directrice exécutive d'Opera.ca, lors d'une entrevue le 19 décembre 2003.

15 Ibid.

16 « Report on Canadian Opera Creation Program Canadian Opera Fund 2002 », p. 2. Document obtenu auprès de Micheline McKay d'Opera.ca.

17 Les informations recueillies pour cette partie proviennent presque exclusivement des brochures officielles des différents conseils des arts ou de leur site Internet. Les citations intégrales sont cependant indiquées comme il se doit.

18 Le CAM fait exception, car le responsable du programme émet une première recommandation à un jury composé de gens d'affaires et de personnalités du milieu artistique.

19 Les critères de sélection sont communs à chacun des programmes d'aide. Il s'agit du rayonnement, de la qualité de gestion et de l'excellence artistique. On relève ensuite de multiples sous-catégo- 
À Opera.ca, les critères de sélection et l'organisation des jurys sont comparables : les jurys sont nommés par le conseil d’administration, et leurs critères visent l'excellence. La subvention accordée ne peut dépasser $50 \%$ des coûts de production. Notons toutefois les différences suivantes : l'organisme doit soumettre un formulaire d'intention de soumission, les administrateurs d'Opera.ca ne font pas partie du jury, un représentant du Conseil des Arts du Canada assiste aux délibérations en tant qu'observateur, et les évaluations sont présentées en anglais (les organismes francophones peuvent obtenir une aide financière pour faire traduire leurs demandes). De plus, lorganisme doit non seulement prouver son engagement envers le répertoire canadien, mais le demandeur principal doit aussi être canadien, et les partenaires doivent être canadiens ou résidents permanents.

\section{Aide AU PROJET ET AU FONCTIONNEMENT}

Les programmes d'aide aux arts sont nombreux, mais seuls quelques-uns nous intéressent plus particulièrement. Il s'agit d'abord des programmes d'aide au projet et au fonctionnement ainsi que de quelques programmes qui permettent aux organismes qui reçoivent déjà un soutien au fonctionnement dobtenir une aide complémentaire pour des projets spéciaux. Laide de projet sert une activité ou un événement particulier, d'une durée déterminée et concentrée, pour lequel un budget a été établi, tandis que l'aide au fonctionnement vise l'ensemble des activités reliées à la programmation régulière d'un organisme. Cependant, les titres de ces programmes portent parfois à confusion : par exemple, les programmes Aide à l'opéra et au théâtre musical du CAC et le Music program du CAT sont des programmes d'aide au fonctionnement; les programmes Aide au projet spécial non récurrent du CAM et Recherche et création du CALQ sont des programmes d'aide de projet spéciaux; et les programmes Compagnie d’opéra et de théâtre musical du CAO et Subventions aux organismes de production englobent les subventions de fonctionnement et les subventions de projets ${ }^{20}$.

Les subventions annuelles ou pluriannuelles réservées à l'opéra se font par l'entremise des programmes Aide annuelle ou pluriannuelle pour l'aide à l'opéra et au théâtre musical (AOTM) du CAC, Compagnie dopéra et de théâtre musical (COTM) du CAO ainsi que par le Music program du CAT.

$\mathrm{Au}$ cours des cinq dernières années, les principaux organismes mentionnés dans cette étude ont tous reçu de l'aide financière de ces trois programmes. À titre d'exemples, le programme AOTM du CAC a consenti depuis 1998-1999

ries auxquelles les organismes doivent répondre, incluant la qualité et le mérite d’un projet - depuis sa conception jusquà sa réalisation - , la stratégie globale de planification, l'engagement vis-à-vis du projet et sa faisabilité.

20 Le Programme général de subventions (CAM) ainsi que les programmes Aide de projet (CAC), Recherche et création (CALQ), Aide au projet (CAM) et Aide au projet spécial non récurrent (CAM) font partie des programmes d'aide qui ne ciblent pas directement le secteur de lopéra. Il existe aussi d'autres programmes qui offrent des bourses aux artistes (compositeurs) ou encore accordent une aide financière pour des projets de tournée. Bien que ces programmes puissent, par défaut, être bénéfiques pour l'opéra, nous nous limiterons aux programmes d’aide spécifiques à l’opéra par l'intermédiaire des programmes d'aide de fonctionnement et de projets spéciaux, ainsi que les programmes d’aide à la résidence, à la commande et à la création. 
des sommes annuelles variant de 30000 \$ à 45000 \$ à Queen of Puddings, de 675000 \$ et 694000 \$ à l'Opéra de Montréal; le programme COTM du CAO a accordé annuellement entre 15000 \$ et 18000 \$à Autumn Leaf Performance et de 33000 \$à 45000 \$ à Tapestry New Opera Works; tandis que Queen of Puddings et Tapestry New Opera Works ont reçu des sommes annuelles respectives d'environ 12000 \$ et 30000 \$ du Music Program du CAT.

\section{Aide À la COMmande ET AU COMPositeur}

Laide à la commande et au compositeur est accordée pour tout type de projet de composition de musique originale canadienne, incluant l'opéra. Les subventions sont octroyées par l'entremise du programme Résidence et commandes de compositions canadiennes (RCCC) du CAC, Commande d'œuvres et résidences du CALQ, Commande d'ouvres musicales du CAO et Music Creators and Composers du CAT.

La place quoccupe l'opéra dans les programmes d'aide à la commande est difficile à évaluer, car les subventions attribuées ne donnent souvent que de l'information sur le compositeur bénéficiaire de l'aide et ne nomment pas systématiquement l'organisme collaborateur, s'il y a lieu. Cependant, puisque les sommes requises pour la composition d'un opéra sont relativement substantielles, nous avons tenté de retracer, sur les sites Internet et dans les rapports annuels, les sommes importantes attribuées aux organismes ou aux compositeurs pour les années 1998 à 2003. Ces recherches ne révélant aucune somme substantielle, nous avons alors contacté quelques compositeurs afin de leur poser la question. Le problème de l'année d'attribution s'est alors posé, et les sommes retracées par nos recherches ne correspondaient pas nécessairement aux sommes reçues par les compositeurs dans les années données. Cependant, les compositeurs joints nous affirment avoir reçu des sommes dans le cadre d'une commande pour un orchestre ou pour des groupes d'instrumentistes plutôt que pour des commandes d'opéras.

Par contre, le CAC se distingue par les sommes attribuées à l'opéra au cours des dernières années au moyen du programme Résidence et commandes de compositions canadiennes, volet Commandes de compositions canadiennes ${ }^{21}$. Laide destinée aux organismes et aux compositeurs, à raison de deux concours par année, permet à des artistes professionnels (solistes, ensembles et organismes) d'engager un compositeur pour la composition d'une œuvre originale (CAC RCCC.1). Les catégories ouvertes aux propositions comprennent la musique pour orchestre, l'opéra, la musique chorale, la musique fonctionnelle (musique de scène et danse), lélectroacoustique et la musique de chambre-musique nouvelle. La subvention accordée sert à payer le cachet du compositeur ou du

${ }^{21}$ Le programme RCCC est divisé en deux volets, soit la résidence et la commande de compositions canadiennes. Au CAC, il existe une personne-ressource pour chaque volet. Dans cette section, les commentaires et statistiques visent seulement le volet Commande de compositions canadiennes. Le volet Résidence sera évalué à la section suivante. 


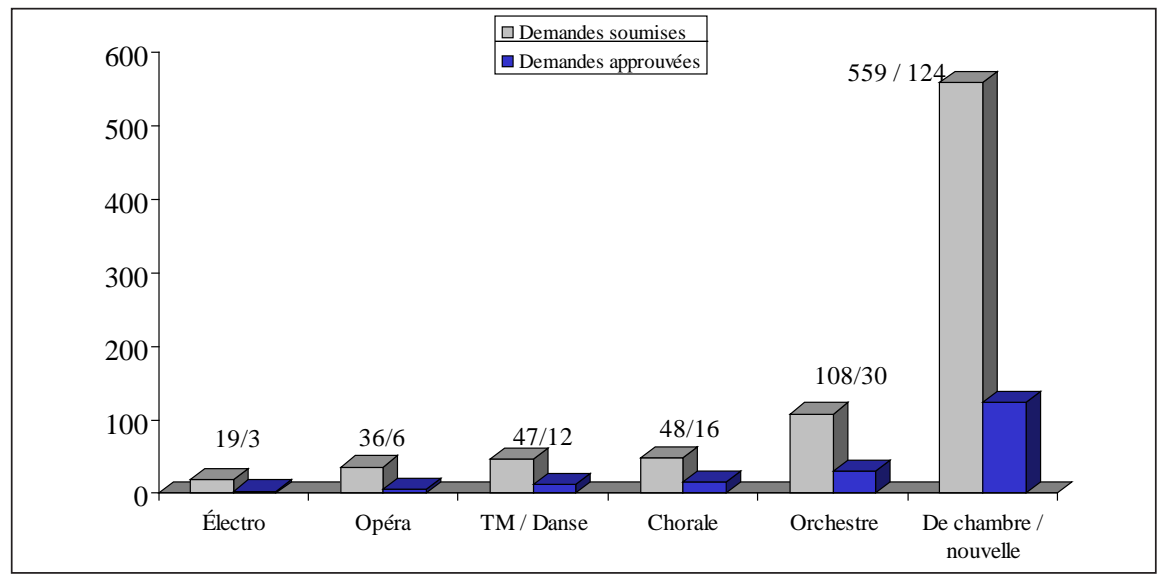

Figure 1: Demandes soumises et approuvées dans le cadre du programme RCCC du CAC de 2000-2001 à 2002-2003

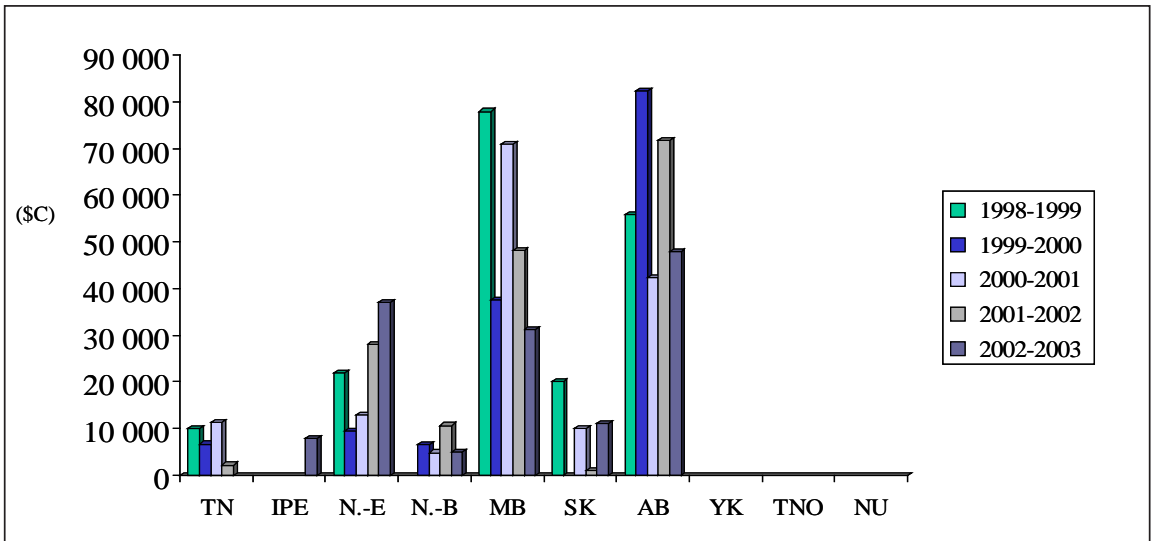

Figure 2a: Aide accordée par le CAC dans le cadre du programme Résidence et commandes de compositions canadiennes pour toutes les provinces sauf le Québec, l'Ontario et la Colombie-Britannique de 1998-1999 à 2002-2003

compositeur et du librettiste. Depuis 2001, les cinq concours évalués ont reçu entre 150 et 180 demandes chacun (voir la figure 1), (CAC RCCC.2) 22.

Les données recueillies démontrent que l'Ontario, le Québec et la ColombieBritannique dominent le panorama de l'aide reçue dans cette catégorie, avec des sommes variant de 105000 \$à 350000 \$ par saison depuis 1998 (CAC RCCC.3). Pour les mêmes saisons, l'Alberta et le Manitoba suivent de près avec une subvention moyenne de $60000 \$$, tandis que les autres provinces reçoivent entre 20 000 \$ et 30000 \$ par année (voir les figures 2 a et 2 b), (CAC RCCC.4).

Les statistiques de la figure 1 révèlent que l'opéra est en avant-dernière place pour le nombre de demandes approuvées. Cependant, il n'y a rien de véritablement étonnant à cet état des choses puisque l'on peut aisément faire le lien

22 Les figures et annexes se trouvent à la fin de l'article. 


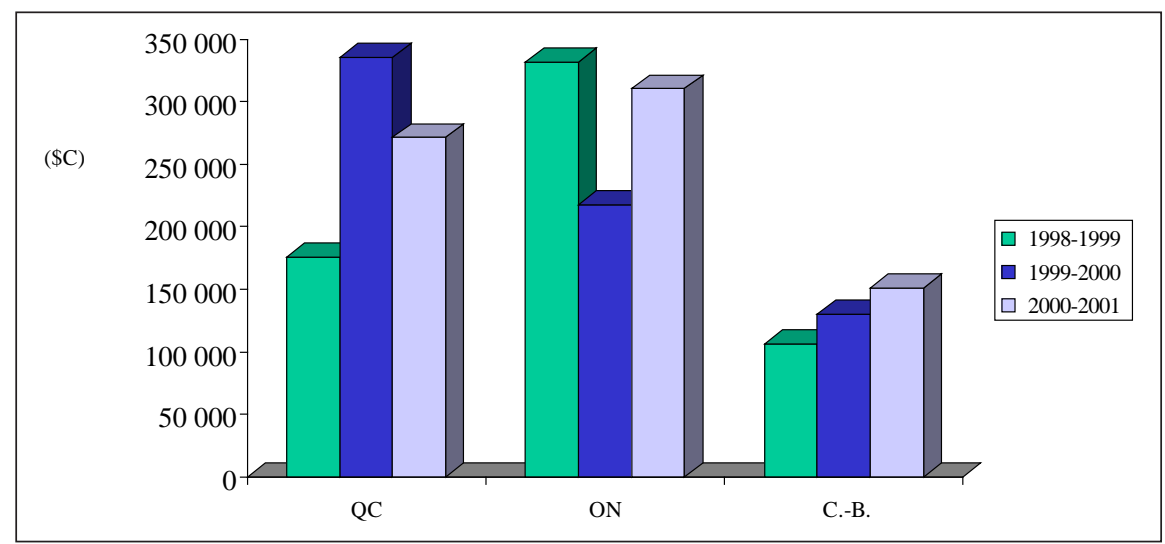

Figure 2b: Aide accordée par le CAC dans le cadre du programme Résidence et commandes de compositions canadiennes pour le Québec, l'Ontario et la ColombieBritannique de 1998-1999 à 2000-2001

entre le nombre de demandes soumises et le nombre de demandes approuvées pour chaque genre, car selon les résultats, la catégorie qui reçoit le plus grand nombre de demandes est aussi la catégorie la plus subventionnée. Existe-t-il un équilibre statutaire entre les genres? Cela est peu probable. Est-ce que le CAC hésite à accorder une aide pour l'opéra, un genre où les débouchés et les probabilités de création de l’œuvre sont moindres que, par exemple, pour une œuvre de musique de chambre? Nous pourrions avancer que oui dans la mesure où les critères des programmes mettent aussi l'accent sur la probabilité de réalisation et la capacité financière de l’organisme hôte à créer l'œuvre commandée.

Puisque l'opéra est un genre coûteux et risqué, c'est donc dire que le Conseil n'accorderait probablement pas de subvention à un organisme dont la situation financière serait mise en danger par la création d'un opéra dont les résultats au guichet sont incertains. Cette politique est-elle une conséquence du phénomène identifié plus tôt, soit l'existence d'un corpus d'opéras plus important que le nombre de créations publiques réelles? Cela est probable. Cependant, le CAC tente de s'assurer d'un certain équilibre, car les mesures des programmes ont été resserrées, et les critères d'exécution sont de plus en plus importants dans le processus des demandes de subventions.

Finalement, les figures 3 et 4 mettent en parallèle les sommes attribuées dans le cadre du programme Aide à l’opéra et au théâtre musical en comparaison avec celles du programme Résidence et commandes de compositions canadiennes. Le CAC subventionne principalement l'opéra par son programme de fonctionnement AOTM et non par le programme RCCC. En effet, une recherche dans les rapports annuels et une consultation de la liste interrogeable des subventions du site Internet du Conseil des Arts du Canada révèlent que seulement quelques organismes producteurs d'opéra ont bénéficié de ce dernier programme depuis 1998, et que les sommes attribuées ne dépassent pas 60000 \$, tandis que le total des subventions de fonctionnement approche ou dépasse le million de dollars par année (il est à noter que les sommes de la figure 4 sont cumulatives par or- 


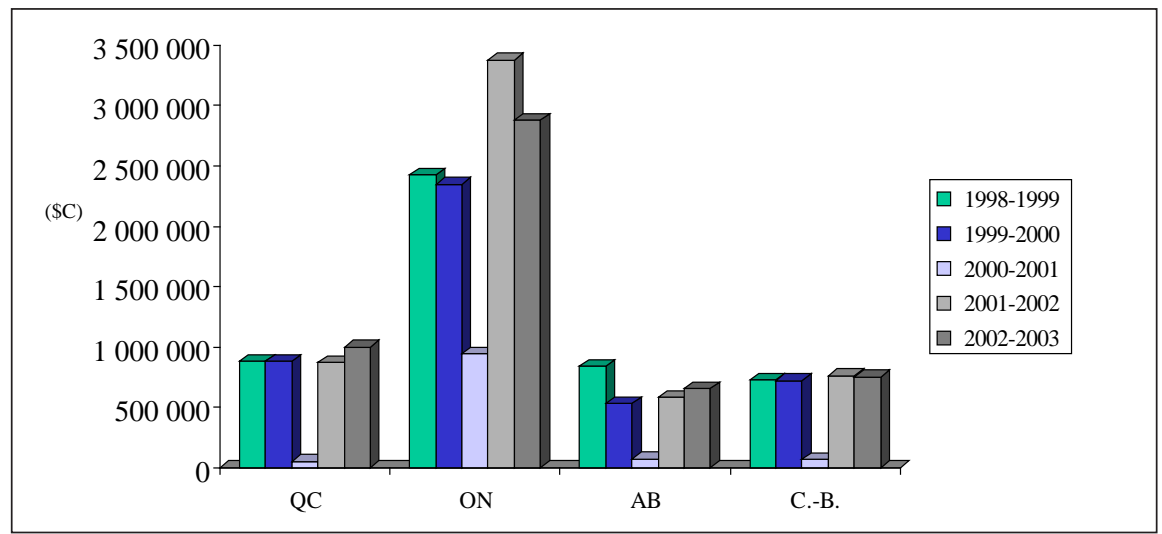

Figure 3a: Aide accordée par le cac dans le cadre du programme aide à l'opéra et au théâtre musical pour le Québec, l'Ontario, l'Alberta et la Colombie-Britannique de 1998-1999 à 2002-2003

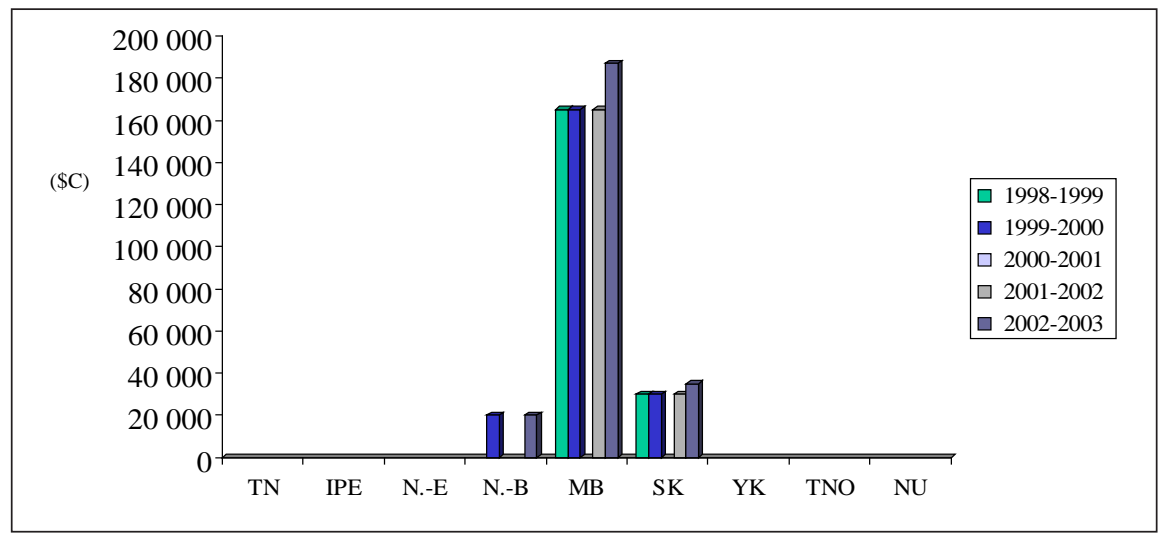

Figure 3b: Aide accordée par le cac dans le cadre du programme aide à l'opéra et au théâtre musical pour toutes les provinces sauf le Québec, l'Ontario, l'Alberta et la Colombie-Britannique de 1998-1999 à 2002-2003

ganisme de 1998 à 2003). De plus, comme il sera expliqué plus loin, la majorité des subventions accordées pour l'opéra dans le cadre du programme RCCC sont destinées à une commande d'œuvre et non à une résidence.

\section{AIDE À LA RÉSIDENCE}

Le volet Résidence du programme Résidence et commandes de compositions canadiennes du CAC ne cible pas directement le secteur de l'opéra, mais soutient plutôt l'engagement de la production et de la diffusion du répertoire cana$\operatorname{dien}^{23}$.

23 Le programme Commandes d'œuvres et résidences du CALQ est une forme d’aide destinée aux artistes et non aux organismes. 




Figure 4: Organismes lyriques ayant reçu des sommes dans le cadre du programme RCCC du CAC de 1998-1999 à 2003-2004 (sommes totales)

Notons toutefois que la Calgary Opera Association (COA) et le Modern Baroque Opera (MBO) possèdent tous deux un programme de résidence non permanent et ont obtenu des subventions du CAC pour des projets de résidence. Dans le cas de la COA, c'est par le biais du programme Composer-in-Residence que l'organisme a accueilli le compositeur John Estacio en 2000. Subventionnée par le CAC pour la période habituelle de deux ans, la COA, satisfaite de son expérience, et grâce au partenariat avec le Centre des arts de Banff, a continué sa collaboration avec le compositeur pour lécriture d'une deuxième œuvre, l'opéra Frobisher. Au cours des dernières années, la COA a reçu des sommes importantes du CAC, soit $20000 \$$ du programme RCCC pour la résidence de John Estacio et environ $355000 \$$ du programme AOTM pour la composition de l'opéra Filumena $\left(\text { John Estacio, }{ }^{\star} 2003\right)^{24}$.

Pour le MBO, l'intérêt pour le nouveau répertoire se traduit par la commande et la production de quatre ouvres nouvelles : 120 Songs for the Marquis de Sade (Peter Hannan, $\left.{ }^{\star} 2002\right)$; Max \& Moritz (Jeff Corness, ${ }^{\star} 2003$ ), un opéra pour la jeunesse ; The Diana Cantata (Peter Hannan, ${ }^{\star} 2003$ ); et Powers of Two (Barry Truax, $\left.{ }^{\star} 2004\right)$, cette dernière œuvre ayant reçu une subvention du CAC pour la résidence du compositeur.

\section{AIDE SPÉCIFIQUE À LA CRÉATION D’OPÉRA}

À Opera.ca, le Programme de création d'opéras canadiens soutient la création et le développement de l'opéra et du théâtre musical au Canada par trois volets,

24 Les modèles d'écriture suivants seront adoptés afin de bien marquer la différence entre les mots «création » pour une première mondiale, et " production » pour une représentation subséquente. Par exemple, l'opéra Kopernikus de Claude Vivier a été créé au Monument national en 1980 et produit, entre autres, par l’Opéra de Montréal en 2001 : Kopernikus (Claude Vivier, ${ }^{\star} 1980$ ) pour une création et Kopernikus, 2001 (Claude Vivier) pour une reprise. Suivant cette logique, une production canadienne peut alors faire référence, par exemple, tant à la première canadienne de Der Ring des Nibelung de Wagner à Toronto quà la première montréalaise de Kopernikus. 
soit Subvention de développement de l'auditoire, Subvention de développement du répertoire et Subvention de perfectionnement de l'artiste.

Règle générale, l'appui accordé couvre un maximum de $50 \%$ des coûts admissibles; l'aide est disponible pour les projets spéciaux et pour la recherche, mais pas pour le fonctionnement, et l'attribution d'une subvention à une étape préliminaire d'un projet ou d'une activité ne garantit pas un appui futur. De plus, Opera.ca encourage particulièrement les collaborations entre les artistes, les créateurs, les compagnies et les communautés puisque la mise en commun des ressources de ces diverses parties augmente la possibilité de créer de nouvelles œuvres tout en diminuant les risques financiers.

Les Subventions de développement de l'auditoire apportent une aide financière aux organismes qui produisent des activités liées à la création ou à la production d'une œuvre canadienne nouvelle ou existante afin qu'ils puissent accroître et diversifier l'auditoire et l'aider à mieux comprendre et à mieux apprécier les œuvres canadiennes nouvelles ou celles qui existent déjà (Opera.ca, 1).

Les Subventions de développement du répertoire servent à couvrir les coûts associés au développement, à la production et aux représentations subséquentes de nouvelles œuvres. La structure des subventions permet à l'organisme d'accéder à une aide à chaque étape du projet, de la mise en place du partenariat au développement de l’ouvre (atelier, lecture, révision), à la production et à la documentation.

Les Subventions de perfectionnement de l'artiste visent à appuyer les compositeurs, les librettistes, les chefs d'orchestre, les concepteurs (costumes, éclairages, décors et autres) et les pianistes répétiteurs qui se consacrent à la création et au développement de l'art lyrique et du théâtre musical canadien.

L'Annexe Ia, compilée d'après les informations recueillies auprès de Micheline McKay, directrice exécutive d'Opera.ca, identifie les récipiendaires et les sommes accordées pour les années d'attribution de 2001-2002 à 2003-2004. En ce qui nous concerne, les sommes accordées dans le cadre des subventions de développement du répertoire sont particulièrement intéressantes, car elles nous donnent une bonne idée de l'activité opératique des prochaines années. De plus, cette liste démontre qu'Opera.ca est un levier essentiel à la création d'opéra au Canada, car lorganisme a subventionné presque toutes les créations d’opéras mentionnées dans cette étude au cours des trois dernières années.

Nous devons faire une parenthèse dans l'aide accordée à l’opéra par des organismes gouvernementaux pour décrire deux programmes importants où la composition d'opéra est stimulée de façon apparemment « artificielle». Tapestry New Opera Works et Pacific Opera Victoria (POV) gèrent respectivement le Composer-Librettist Laboratory et le Composer Librettist Laboratory and Development Program. Ces programmes fonctionnent de manière similaire, c'est-à-dire en réunissant des groupes d'auteurs et de compositeurs présélectionnés par l'organisme pour une durée d'environ sept jours. Des équipes sont formées en vue de collaborer à la création d'un opéra. La plupart des compositeurs participants en sont à leur première expérience dans le domaine de la composition d'un opéra, mais cela n'empêche pas les dirigeants de leur soumettre une 
offre de développement ou même une commande si l'œuvre présentée est jugée valable.

Le Canada n'est pas le seul pays à soutenir ce genre d'entreprise dans le domaine. Il y a, entre autres, Aldeburgh Music, de Suffolk en Angleterre, qui gère aussi un laboratoire de composition. D’une durée de six jours, ce programme réunit dix compositeurs et dix poètes. Les équipes composent rapidement des opéras et des scènes d’opéra (Higgins 2001, 12). Ayant pour modèle le Centre des Arts de Banff, Aldeburgh Music reçoit des subventions annuelles et son centre de développement professionnel est en activité toute l'année.

Nous assistons donc à une étonnante institutionnalisation de la créativité, au point où l'on est en droit de se demander si l'inspiration ne s'y trouve pas un peu « forcée ». Les participants ne s'entendent pas sur une raison en particulier pour expliquer les raisons dêtre de ce nouveau concept de création " artificielle ". Cependant, dans un article intitulé " Canadian Overtures ", Eric Domville suggère que la géographie de notre pays est partiellement responsable de l'apparition des laboratoires de composition, car ceux-ci permettent de contrer la vaste étendue de notre pays en réunissant les artistes (Domville 2003, 22).

Le lien entre les laboratoires de composition et la géographie est particulièrement intéressant, car le besoin de former de tels regroupements témoigne de léclatement du pays. Il est donc pertinent de se questionner à savoir si la production " artificielle » d’opéra dans un processus " forcé » ne remet pas en question le principe de l'identité nationale. Lart en général est souvent considéré comme le reflet de la société, et la musique, l’art vocal en particulier, a joué plusieurs rôles dans l'histoire, comme celui de véhicule de revendication ou celui de forme d'expression identitaire puissante ou unificatrice. Les œuvres créées par l'entremise de ces laboratoires ne possèdent aucune de ces caractéristiques, car les sujets ou thèmes abordés sont choisis par le duo créateur dans le but de répondre à une exigence de "fabrication » et non à un désir pur d'expression ou de création artistique.

Notons aussi que les laboratoires de compositions se trouvent en Ontario et en Colombie-Britannique, deux des trois principaux centres culturels du Canada, où toutes les ressources et infrastructures nécessaires à la création existent déjà. L'existence de ces laboratoires ne semble donc pas poursuivre un but éducatif, quoique le tout soit probablement circulaire, car sans les infrastructures déjà présentes, les laboratoires ne pourraient exister. Il est important d'ajouter que ces laboratoires reçoivent une aide financière, entre autres du CAC et de la Laidlaw Foundation, sans laquelle ils ne pourraient exister. On ne peut s'empêcher de percevoir ces laboratoires comme une entreprise de fédération quelles qu’en soient les conséquences sur la création ${ }^{25}$.

25 Bien que la distinction entre inspiration et «fabrication " (notion en rapport ici avec celle de " commande ") est délicate à appliquer aux œuvres $\mathrm{du} \mathrm{xx}^{\mathrm{e}}$ siècle, les conclusions que nous donnons quant aux moteurs d'inspiration et de commande nous semblent justifiées dans la mesure où ces conclusions s’appuient sur un échantillonnage limité d’œuvres qui nous permet détablir cette distinction. Il ne s'agit pas détablir ici une définition applicable sur une plus grande échelle. 


\section{RELATION ENTRE LES PROGRAMMES}

Les sommes attribuées globalement au secteur de lopéra par les conseils des arts des ordres fédéral, provinciaux et municipaux, excluant Opera.ca, représentent un pourcentage considérable du budget total d'un organisme. Par exemple, il est d'environ 25 à $27 \%$ pour la Canadian Opera Company et de $27,1 \%$ pour la Calgary Opera Association. Les organismes lyriques, quant à eux, reçoivent proportionnellement un peu plus, soit environ $40 \%$ pour Tapestry New Opera Works et environ $60 \%$ pour Chants Libres ${ }^{26}$. Cette aide est donc d'une très grande importance. Cependant, la description de la structure des différents programmes d'aide démontre bien que, dans la plupart des cas, les sommes accordées servent au fonctionnement des organismes et non à la création en tant que telle d’opéras. Les projets de création nécessitent donc une aide particulière, car l'analyse des différents programmes d'aide confirme que les programmes d'aide réguliers jouent un rôle décroissant quant à lévolution du répertoire contemporain canadien. La création musicale dans le domaine de l'opéra doit donc s'en remettre à des programmes de création d’opéras canadiens comme celui d'Opera. ca et aux initiatives indépendantes des programmes gouvernementaux.

Plusieurs éléments sont toutefois en place pour aider à résoudre le problème de la création en opéra : le CAC consacre des sommes spéciales à lopéra par l'intermédiaire d'Opera.ca, qui les redistribue ensuite selon ses propres critères; la $\mathrm{COC}$ et la $\mathrm{COA}$, qui gèrent toutes deux des programmes de compositeur en résidence, parfois aidées d'une subvention et parfois à leurs frais, accueillent des compositeurs de renom dans le but de composer un opéra; la COC, par exemple, a commandé The Scarlett Princess (Alexina Louie, ${ }^{\star} 2002$ ), par l'entremise de son programme Composer in Residence, tandis que quatre de ses dernières commandes, dont Inanna's Journey, l'opéra à venir de Randloph Peters, sont des projets commandés en dehors du programme; et plusieurs organisations artistiques privilégient maintenant les coproductions alors que d'autres ont carrément fusionné pour contrer les difficultés financières, mais aussi pour renforcer leur structure administrative et artistique. C'est le cas, par exemple, de la compagnie Opera Lyra et du Centre national des arts d'Ottawa, ainsi que des compagnies dopéra des villes de Kitchener et de Hamilton, en Ontario, qui ont fusionné pour former Opera Ontario.

L'importance d'arrimer les projets de productions avec les projets de commandes devient de plus en plus essentielle. Il est certain que l'assurance de financement au projet ou au fonctionnement et l'octroi d'une subvention pour un projet de commande favorisent la création de nouvelles œuvres. Mais à quel prix? Cette méthode de " concentration " peut être illustrée par l'un des projets de la COA qui, en 2002, a reçu 20000 \$ pour la résidence de John Estacio, alors que son partenaire, le Calgary Philharmonic Orchestra, a aussi reçu une subvention du même montant pour le même projet. Ces sommes combinées ont

26 Informations recueillies auprès de : Bob McFee (Calgary Opera Association) le 12 novembre 2003; Anna Camara (Tapestry New Opera Works) le 11 novembre 2003; Louise Dugas (Chants Libres) le 11 novembre 2003; et par la consultation des rapports annuels de la Canadian Opera Company de 1997 à 2002 . 
permis aux organismes non seulement de produire une œuvre qui semble avoir conquis tant la critique que le public, mais aussi d'en assurer une exécution de qualité.

Si les conseils des arts offrent des subventions dans le cadre de programmes de résidence, l’opéra en bénéficie peu ou pas du tout, car la grande majorité des maisons d'opéra du Canada ne possèdent pas de programme de résidence et reçoivent de rares subventions par l'entremise d'un programme de commande ${ }^{27}$.

Finalement, à moins que les maisons d'opéra ne complètent substantiellement les sommes versées, les montants accordés pour un projet ne leur permettent pas de créer un programme de résidence permanent qui assurerait le développement de projets solides. Force est de constater que, dans la situation économique de la dernière décennie, malgré le regain de popularité de l'opéra et son grand succès de vente de billets, les grandes maisons d’opéra ne semblent pas être en mesure de se permettre de tels projets. On imagine alors que les organismes aux ressources financières moins importantes comme le Manitoba Opera, Opera Lyra, Opera Ontario et l'Opéra de Québec le peuvent encore moins.

\section{LES ORGANISMES DU QUÉBEC ET DE L'ONTARIO QUI BÉNÉFICIENT DE L'AIDE OFFERTE PAR LES CONSEILS DES ARTS ET OPERA.CA}

\section{L'Opéra de Montréal et la Canadian Opera Company}

L'Opéra de Montréal et la Canadian Opera Company sont les deux grandes institutions de production d'opéra au Canada. L'Opéra de Montréal a fait sa marque en présentant environ 600 représentations de 76 opéras, dont 30 nouvelles productions canadiennes, tandis que la COC de Toronto s'est taillée une place de choix en tant que la plus grande maison productrice d'opéras canadiens et l'une des plus grandes maisons de production en Amérique du Nord avec une vingtaine de premières canadiennes et autant de premières mondiales.

Lavantage de la COC sur l'OdM s'explique par plusieurs facteurs : L'OdM (fondé en 1980) est relativement jeune comparativement à la COC (fondé en 1950); en 22 ans, l'OdM n'a connu que trois directeurs artistiques dont les deux précédant Bernard Labadie sont reconnus pour leur esthétique diamétralement opposée ${ }^{28}$, tandis qu’un grand épanouissement marque la décennie 1980-1990 pour la COC grâce à l'esprit créatif et la vision artistique élargie de Richard Bradshaw; L'OdM possède un budget de 9 millions de dollars (Kaptainis 2003, 24), tandis que le budget de la COC se chiffre aujourd'hui à environ 15 millions de dollars. Les possibilités sont donc beaucoup plus nombreuses; plus important encore, la COC bénéficie d'une meilleure intégration dans la société torontoise

27 Notons cependant qu'une recherche visant à comparer les différents programmes de résidences du Canada à ceux des États-Unis et de l'Europe révèle que ces pays possèdent peu ou pas de programmes de résidences dans les maisons d’opéra. Après réflexion, il nous apparait que la résidence ne favoriserait pas nécessairement le succès d'une création, quoique la qualité en serait probablement améliorée par le niveau élevé de créativité de l’environnement et l’accès direct aux collaborateurs.

28 Depuis sa création, l'Opéra de Montréal a connu trois directeurs artistiques : Jean-Paul Jeannotte (1980 à 1989), Bernard Uzan (1989 à 2001) et Bernard Labadie (2002-2006). 
et un appui du public plus constant et plus important qu'à l'OdM. Les succès des collectes de fonds en sont d'ailleurs un indice remarquable. Pour la saison 20012002, la COC estime que $35 \%$ de ses revenus proviennent de ses collectes de fonds, soit $8 \%$ de plus que les $27 \%$ reçus par les subventions fédérales, provinciales et municipales (COC, Rapports annuels 1997-1998 à 2001-2002). Pour la saison 2002-2003, cet écart est réduit à $5 \%$, car la COC estime que $31 \%$ de ses revenus proviennent de ses collectes de fonds, tandis que $26 \%$ proviennent de subventions fédérales, provinciales et municipales. À titre de comparaison, pour la Calgary Opera Association, la collecte de fonds atteint $26 \%$, et la vente de billets procure $46 \%$ du budget d'exploitation ${ }^{29}$, tandis que pour l'Opéra de Montréal, la collecte de fonds atteint $12 \%$, alors que la vente de billets procure $45 \%$ du budget d'exploitation ${ }^{30}$.

La COC sefforce depuis plusieurs années de faire de l'opéra canadien un " produit culturel » d'une aussi grande valeur que toutes les œuvres du répertoire privilégiées par les amateurs. D’ailleurs, c’est dans le but de faciliter le développement de nouveaux opéras canadiens qu'elle a établi en 1987 le programme Compositeur en résidence. Les opéras Réalitillusion (Michel-Georges Brégent, ${ }^{\star}$ 1988), Zoé (Richard Désilets, ${ }^{\star} 1988$ ), Dreamplay (Timothy Sullivan, ${ }^{\star} 1988$ ) et An Expensive Embarrassment (Denis Gougeon, ${ }^{*} 1989$ ) appartiennent aux expériences prudentes des deux premières saisons du programme ${ }^{31}$.

Le succès retentissant de ces créations incite toutefois la COC à prendre le risque bien calculé de présenter des opéras complets au public depuis la saison 1990-1991. Les œuvres incluent, entre autres, Guacamayo's Old Song and Dance (John Oliver, ${ }^{\star} 1991$ ), Nosferatu (Randolph Peters, ${ }^{\star} 1993$ ) et Red Emma (Gary Kulesha, $\left.{ }^{\star} 1995\right)$. Ces trois opéras ont obtenu des succès d'assistance sans précédent, remplissant respectivement des salles à des capacités de $79 \%, 99,8 \%$ et à guichets fermés. Concrètement, cela représente 400 à 450 spectateurs par soir pour environ trois représentations par opéra ${ }^{32}$. Exploit encore plus rare, les pré-ventes de la Calgary Opera Association atteignent fréquemment $94 \%$ de la capacité de la salle, et ce, même pour les créations : l'opéra Filumena de John Estacio a reçu sa première en février 2003 avec deux de ses trois représentations à guichets fermés dans une salle de 2700 places $^{33}$.

La COC a aussi pris des risques qui se sont avérés constructifs, comme celui d'engager des artistes au grand potentiel créateur comme Atom Egoyan et Robert Lepage notamment, pour la mise en scène d’opéras, tandis que la programmation très conservatrice de Bernard Uzan à l'Opéra de Montréal a ré-

29 Information recueillie auprès de Bob McPhee le 12 novembre 2003.

30 Information recueillie auprès d'Anja Nopper, le 2 juin 2004. Pour une synthèse des sources de revenus des principaux organismes de cette étude, voir l'Annexe 3.

31 La COC avait imposé les conditions suivantes aux compositeurs : un acte d'une durée maximale de soixante minutes et un maximum de six chanteurs et cinq musiciens.

32 Guacamayos Old Song and Dance a été présenté trois soirs à l'Imperial Oil Opera Theatre du Joey and Toby Tanenbaum Opera Centre de la COC, une salle de 450 places; Nosferatu a été présenté trois soirs au du Maurier Theatre Centre du Harbourfront Centre de Toronto, une salle de 400 places; et Red Emma a aussi été présenté au du Maurier Theatre Centre pour une durée indéterminée, mais probablement trois ou quatre soirs.

33 Filumena a reçu sa première au Main Hall du Jubilee Auditorium. 
duit peu à peu l'intérêt des abonnés. Le manque de dynamisme artistique de la compagnie et cette programmation conservatrice provoquèrent une réaction de repli de la part des gouvernements, qui se sont contentés de maintenir leur appui ou l'ont diminué.

Finalement, l'arrivée de Bernard Labadie au poste de directeur artistique en 2002 avait ravivé les espoirs pour un opéra qui exploiterait de façon équilibrée, les veines traditionnelles, innovatrices et créatives à Montréal. Cependant, sa démission en août 2006 remet une fois de plus les collaborations tant espérées en suspens et inquiète sans doute, car plusieurs intervenants du milieu, dont certains représentants des conseils des arts, croient fortement que l'épanouissement de la création au Québec est intrinsèquement lié à la collaboration entre la compagnie d’opéra et l'organisme lyrique.

\section{Les compagnies lyriques}

Les compagnies lyriques produisant des opéras canadiens existent un peu partout au Canada, mais elles se concentrent surtout en Ontario (voir l'Annexe 2). En général, ce sont des compagnies qui profitent du développement des nouvelles technologies en combinant des techniques vocales et instrumentales expérimentales aux techniques électroacoustiques et de la bande vidéo. Pour les besoins de notre démonstration, seules les compagnies se préoccupant uniquement de création ont été retenues. Pour le Québec il s'agit de Chants Libres, et pour l'Ontario, il s'agit de Autumn Leaf Performance, Queen of Puddings et Tapestry New Opera Works ${ }^{34}$.

En général, ce sont des compagnies avant-gardistes, constantes dans leurs productions de créations, au rythme d'une par année habituellement. Elles profitent du développement des nouvelles technologies en combinant des techniques vocales et instrumentales expérimentales aux techniques électroacoustiques et de la bande vidéo. Le résultat est innovateur et vaut à certaines compagnies, dont Tapestry New Opera Works et Chants Libres, une réputation internationale.

Létude du fonctionnement des compagnies lyriques nous apprend que la création repose de plus en plus sur les compagnies spécialisées. Parce que les grandes maisons d’opéra semblent s’en tenir au répertoire connu, les petites compagnies spécialisées prennent en charge le développement des nouvelles œuvres, assument les risques et innovent sur les plans artistiques, sonores et scéniques. Nous sommes donc témoins du transfert de la charge de la création des grandes maisons d'opéra vers les petites compagnies lyriques spécialisées. Cependant, si l'importance des compagnies lyriques se détermine par le finan-

34 Il importe cependant de mentionner qu'il existe plusieurs autres compagnies lyriques qui n'ont pas pour mission de produire du répertoire canadien, mais qui s'aventurent tout de même dans la création ou la reprise d'œuvres canadiennes. C'est le cas, par exemple, de Amphion Opera (Toronto), Opera Breve (Vancouver), Opera in Concert (Toronto) et du Modern Baroque Opera (Vancouver). Il existe aussi des organismes qui célèbrent un anniversaire important avec la création exceptionnelle d'un opéra. Nos recherches nous indiquent que ces divers organismes sont assez nombreux. Cependant, compte tenu des objectifs que nous nous sommes fixés dans cette étude, nous avons exclu les projets ponctuels et les compagnies n’ayant pas pour mission la création canadienne. 


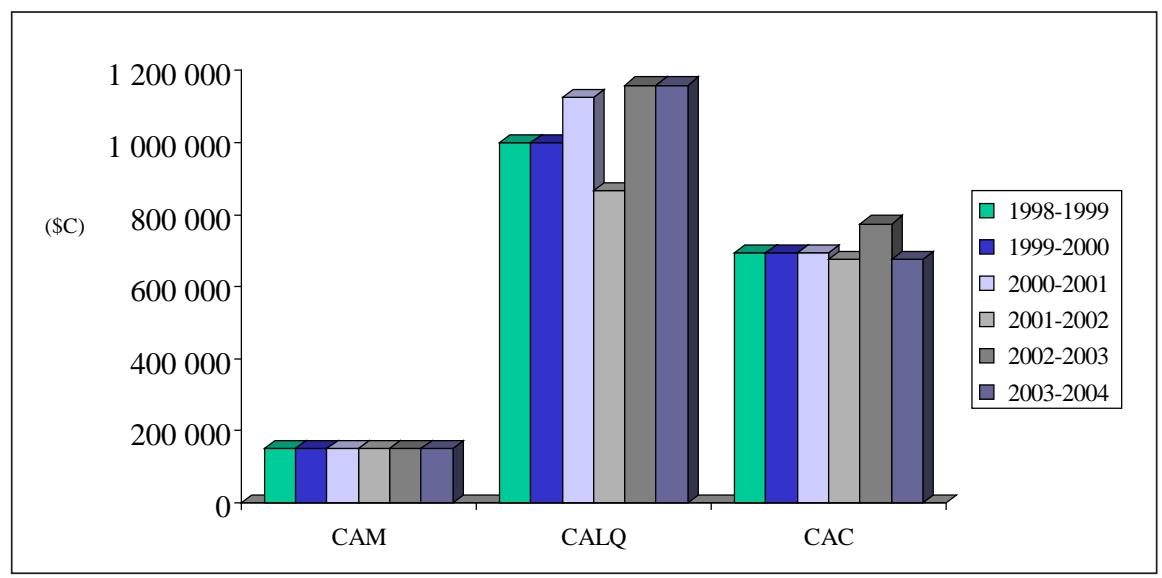

Figure 5: $\quad$ Aide accordée à l'opéra de Montréal par le CAM, le CALQ et le CAC de 19981999 à 2003-2004

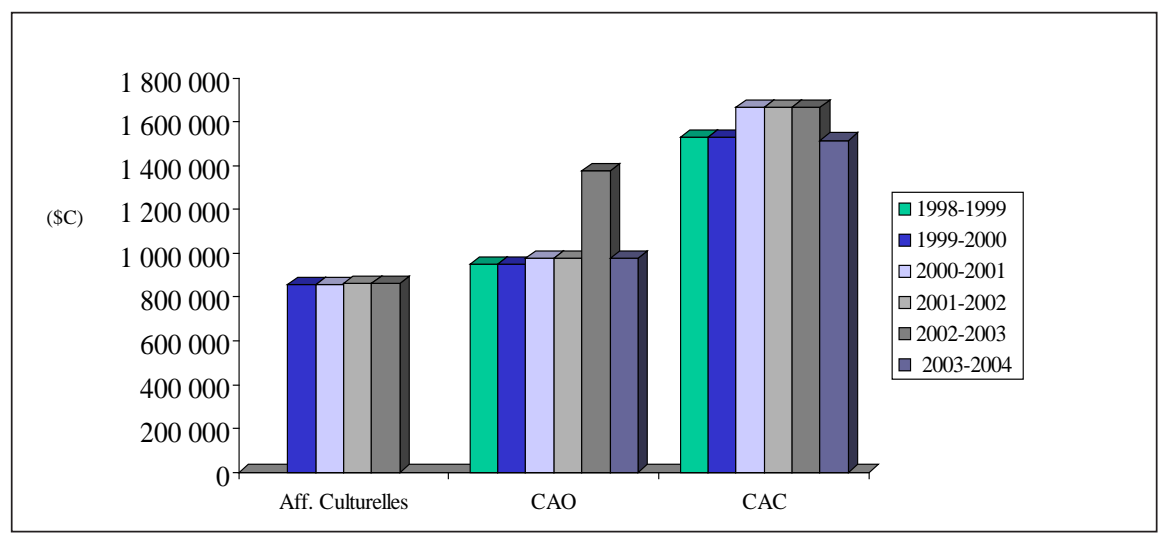

Figure 6: $\quad$ Aide accordée à la Canadian Opera Company par le Département des affaires culturelles de la ville de Toronto, le CAC et le CAO de 1998-1999 à 2003-2004

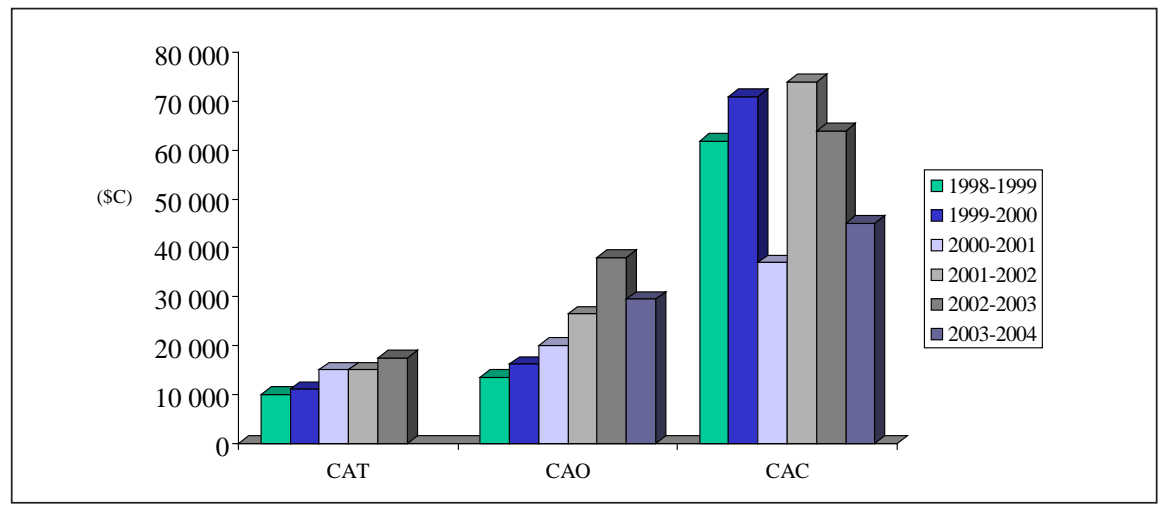

Figure 7: Aide accordée à Queen of Puddings par le CAT, le CAO et le CAC de 1998-1999 à 2003-2004 


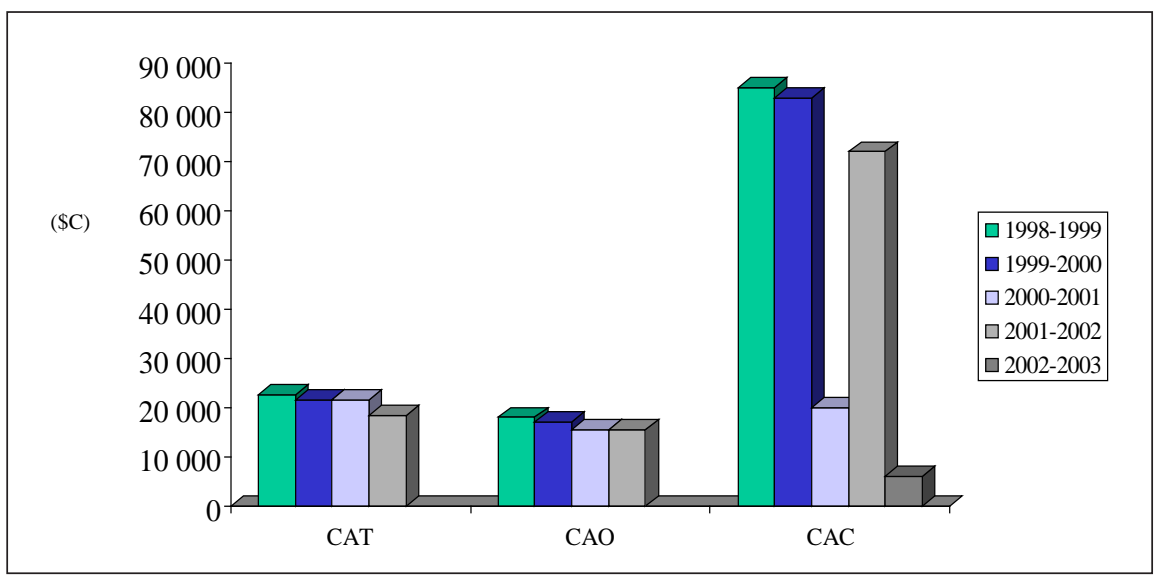

Figure 8: Aide accordée à autumn leaf performance par le CAT, le CAO et le CAC de 1998-1999 à 2002-2003

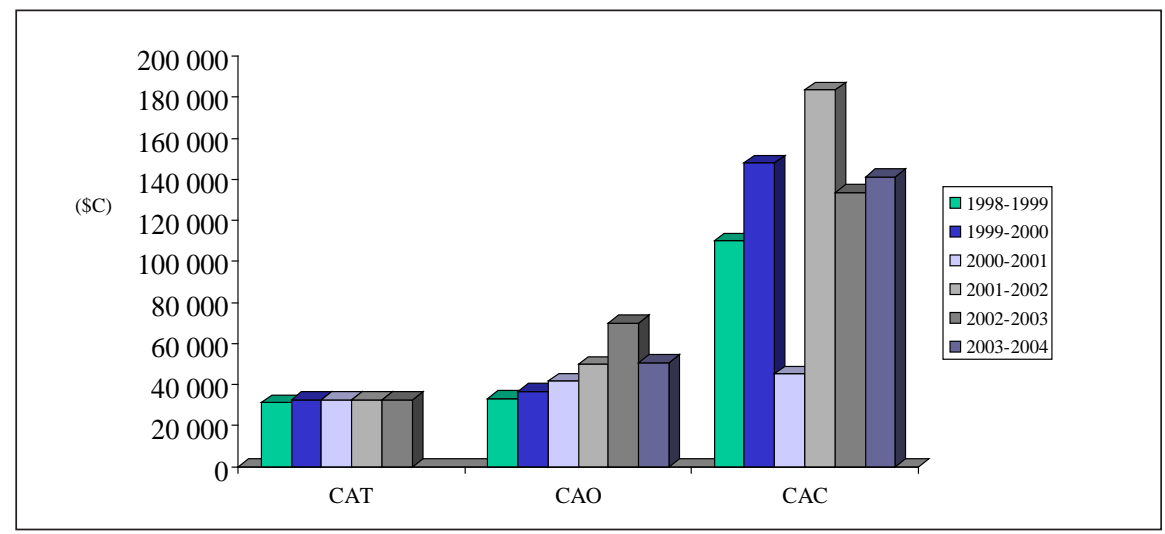

Figure 9: Aide accordée à tapestry new opera works par le CAT, le CAO et le CAC de 1998-1999 à 2003-2004

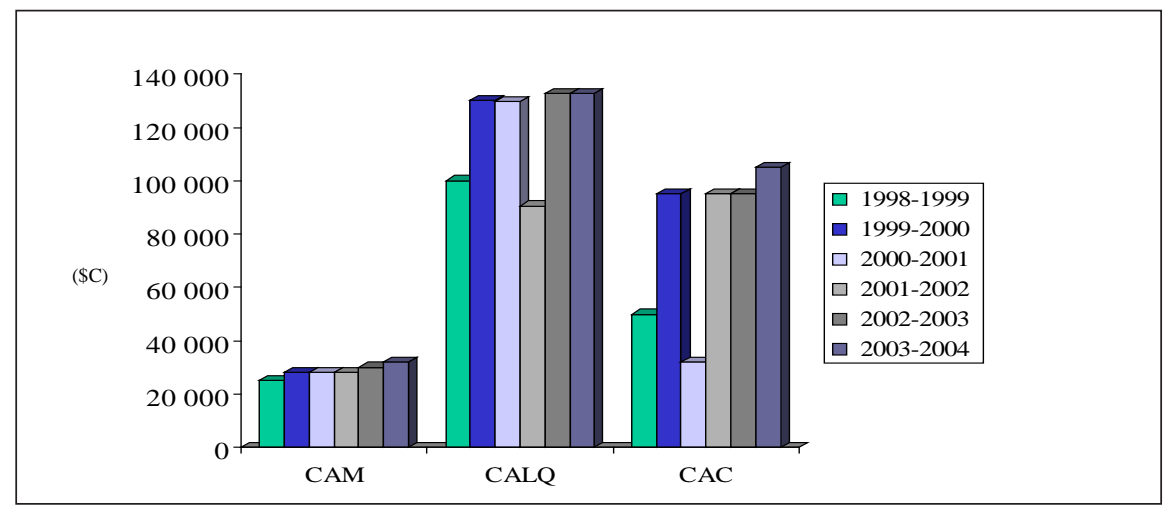

Figure 10: Aide accordée à chants libres par le CAM, le CALQ et le CAC de 1998-1999 à 2003-2004 
cement qu'elles reçoivent, il va sans dire que la création au Québec et en Ontario est valorisée (voir les figures 5 à 10).

Les ateliers et les programmes de développement de l'auditoire

La formation entourant l'opéra se divise en deux grands axes : la formation d'une relève professionnelle par l'entremise des ateliers d’opéra et la formation des auditeurs par l'intermédiaire de multiples initiatives de la part des compagnies. Dans les sections suivantes, nous explorerons l'importance de la formation de nouveaux talents ainsi que les efforts consentis pour attirer le public dans les salles de spectacle. Le genre ne pourrait exister sans ces deux composantes ni, par le fait même, la création de nouveaux opéras.

L'étude des ateliers, qu'ils soient rattachés à une maison d'opéra ou à une université, a pour but dévaluer leur contribution projetée sur la formation de la relève ainsi que sur le développement du goût pour la création.

Les ateliers

Il existe au Canada deux grands ateliers rattachés à des maisons d’opéra, soit le Canadian Opera Company Ensemble Studio (1980) et l'Atelier lyrique de l'Opéra de Montréal (1984). Parmi les ateliers importants rattachés à une université, il y a la Division d'opéra de la Faculté de musique de l'Université de Toronto (1946), le Studio d'opéra de McGill (1956), l'Atelier d’opéra de l'Université de Montréal (1975), l'Atelier lyrique de l'Université du Québec à Montréal (1978) et l'atelier d'opéra de l'Université Laval (1981) ${ }^{35}$.

Les deux types d'ateliers représentent des éléments essentiels pour la formation de jeunes chanteurs et une recherche au sujet des diplômés de ces programmes nous permet de constater que plusieurs travaillent dans le domaine des arts, chantent professionnellement ou évoluent en tant quéducateurs dans le domaine de l'opéra. L'Atelier d’opéra de l'Université de Montréal a formé, entre autres, les voix de Noëlla Huet, Nathalie Paulin et Daniel Taylor et les diplômés du Canadian Opera Company Ensemble Studio incluent Ben Heppner, Gidon Saks et Isabel Bayrakdarian (Morey \& Morris 1993, 499). La Division d'opéra de l'Université de Toronto a aussi révélé plusieurs excellents chanteurs, notamment Nancy Herminston, Rosemarie Landry, Phyllis Mailing, Mark Pedrotti, Gino Quilico, Bernard Turgeon et Robin Wheeler. La contribution projetée sur la formation de la relève est donc concrète.

Par contre, même si les chanteurs formés par les ateliers font de brillantes carrières et se retrouvent, plus tard, au sein de ces ateliers comme éducateurs, cela ne semble pas influencer le type de répertoire joué qui, lui, n'est pas nécessairement canadien. Le répertoire des ateliers reste traditionnel et s'enrichit parfois, mais rarement, de nouvelles œuvres canadiennes. En général, les ateliers universitaires du Canada ne comptent que deux ou trois productions canadiennes à leur répertoire, par exemple Taptoo! (John Beckwith, ${ }^{\star} 1999$ ) pour le Studio d’opéra de McGill, Le Prix, (Jacques Hétu, ${ }^{*}$ 1993) pour l’Atelier lyrique de

35 Plusieurs ateliers ont changé de nom depuis leur formation. Les dates ci-haut réfèrent à l’année de fondation de latelier, parfois sous un nom différent. 
I'UQAM ainsi que Kopernikus, (Claude Vivier, $\left.{ }^{\star} 1980\right)$, et Exercices de conversation et de diction françaises pour étudiants américains et Exercices de style, 2003 (José Evangelista) pour l'Atelier d'opéra de l'Université de Montréal. La Division d’opéra de la Faculté de musique de l'Université de Toronto se démarque avec plusieurs premières ou reprises, dont Aria da capo, 1963 (Raymond Pannell), The Last Duel (Gary Kulesha, ${ }^{\star} 2000$ ) et Taptoo!, 2003 (John Beckwith).

Les chanteurs nont donc pas vraiment loccasion d'explorer le répertoire contemporain et de s'y découvrir des affinités au cours de leurs ateliers de formation. Somme toute, les coordonnateurs des programmes expliquent que le répertoire contemporain, souvent difficile à déchiffrer, nécessite un bagage musical qui excède celui dont dispose l'étudiant. La possibilité de jouer du répertoire contemporain diminue avec de jeunes voix en formation.

Pour parer à cette réalité, les organismes tels que Chants Libres et Queen of Puddings offrent des stages dété qui permettent aux étudiants de se familiariser avec les particularités de la musique actuelle tout en apprivoisant des outils qui les aideront à développer les habiletés vocales et dramatiques que requièrent les productions d'opéras contemporains. Plus important encore, ils encouragent les jeunes chanteurs à se présenter aux auditions de leurs nouvelles productions et leur proposent des rôles à leur mesure.

Létude du fonctionnement des ateliers montre que l'investissement dans l'éducation entraîne des résultats positifs quant à la formation de la relève, mais non pour le développement du goût pour la création ni pour la création en tant que telle.

\section{LES PROGRAMMES DE DÉVELOPPEMENT DE L'AUDITOIRE}

La nécessité de grossir les rangs du public est une préoccupation constante des maisons d’opéra et des compagnies de création. Les différents organismes consacrent donc beaucoup de temps et dénergie à développer des stratégies pour réduire le fossé qui se creuse entre le public et la scène. Nos recherches concluent que le développement et l'accroissement du nombre de spectateurs est stimulé par trois actions principales, soit les rabais sur les représentations (avec des mesures s'appliquant tout autant au répertoire " habituel » qu'aux œuvres contemporaines, telles que les réductions pour les spectateurs âgés de moins de 16 ans, pour ceux âgés de 17 à 30 ans, la vente de billets pour trois opéras pour le prix de deux, et ainsi de suite); la formation du public adulte par les conférences, les ateliers et les voyages éducatifs; et les conférences et les volets éducatifs pour la jeunesse (atelier, études d’ouvres, mini créations parfois présentées devant public, visite de la maison d’opéra locale, camp).

Globalement, l'information recueillie révèle que les maisons d’opéra misent sur des politiques de billets à rabais pour attirer un plus grand public, mais concentrent leur énergie sur les programmes éducatifs pour le jeune public en ce qui concerne la création et sur les conférences pour adultes. Les compagnies lyriques font de même, mais elles ont moins de moyens et rejoignent un plus petit nombre de jeunes. Ces actions nont aucune incidence directe sur la création, mais elles éduquent, attirent ou maintiennent un public intéressé. Les 
initiatives de développement de public adulte ont peu ou pas d'influence sur létablissement d'un véritable contact entre ce dernier et la création. La plupart des compagnies misent davantage sur l'éducation du jeune public et sa sensibilisation au processus créateur. C'est d'autant plus vrai que l'initiation à l'opéra se fait souvent par l'entremise de programmes de création. On compte ainsi au moins trois créations d’opéra pour la jeunesse dans la région de Toronto chaque année. Évidemment, le niveau d'accessibilité du texte et/ou de la musique ainsi que l'envergure des œuvres se mesurent sur une échelle différente de celle des productions dites pour adultes. Cependant, dans le cadre de notre travail nous pouvons conclure que l'opéra pour enfants bénéficie positivement des politiques institutionnelles concernant la création d’opéra au Canada.

\section{LE CONTEXTE ACTUEL DE LA CRÉATION D’OPÉRA AU CANADA}

Lévaluation et la description des programmes d'aide qui précèdent permettent une compréhension globale des mécanismes qui régissent les relations entre les bailleurs de fonds et les principaux acteurs du milieu de l'opéra. La section qui suit à pour objectif de mieux comprendre la dynamique contemporaine qui entoure le phénomène de la commande d'une œuvre musicale dans le contexte décrit précédemment. Lanalyse des tendances entourant la commande et la création d'un opéra va mettre en évidence les relations entre les politiques institutionnelles et la création d’opéra au Canada ${ }^{36}$.

Rappelons donc nos interrogations de départ puisquelles forment la base des données recueillies pour cette section : Quels sont les principaux mécanismes qui régissent la commande et la création d'un opéra? Est-ce que la création d’opéra peut exister sans l'aide accordée par le gouvernement? L'aide gouvernementale constitue-t-elle une contrainte artistique pour les créateurs? La création d'opéra ne devrait-elle pas se tourner vers d'autres sources d'appui afin de s'affranchir du circuit étatique mis en place il y a une trentaine d'années? Le genre de l’opéra constitue-t-il vraiment un élément fondamental de l'identité artistique canadienne ${ }^{37}$ ?

36 Dans notre mémoire de maîtrise, des propos de compositeurs, interprètes et directeurs artistiques nous ont permis d'explorer en détail divers éléments entourant et régissant la commande d'un opéra, d'analyser les diverses influences du milieu culturel sur la création ainsi que de nous pencher sur la raison d'être de l'opéra contemporain au Canada. En raison du cadre imparti à cet article, la démonstration a dû être considérablement abrégée.

37 Par souci de bien représenter la situation de l'opéra au Canada, nous avons posés ces questions à des personnalités « clés " du milieu, soit les directeurs de programmes de subventions des conseils des arts, les directeurs artistiques des maisons d’opéra et des organismes lyriques étudiés, quelques directeurs des communications, directeurs généraux et directeurs du marketing, quelques compositeurs dont l'intérêt pour l'opéra était évident et qui ont une carrière dépassant les frontières du Canada ainsi que quelques artistes. Pour ces derniers, nous avions envisagé des personnalités de réputation internationale qui devaient aussi être très actives sur la scène canadienne et des chanteurs provenant des ateliers rattachés aux maisons d’opéra, recommandés par les directeurs. Dans le cas des artistes établis, la plupart d'entre eux étaient en répétition (souvent à létranger), et malgré leur enthousiasme, nous n'avons pu recueillir leur propos. Au-delà de la non-disponibilité, on est en droit de se demander si le sujet de l'entrevue, l'opéra contemporain au Canada, nétait pas « difficile » et ne créait pas un certain malaise. De plus, nous n'avons pu rencontrer les chanteurs en formation car les directeurs étaient réticents à les déranger. Il est à noter que les réponses à nos questions ont été enregistrées lors d’entrevues de vive voix ou envoyées par 


\section{LES MÉCANISMES QUI RÉGISSENT LA COMMANDE ET LA CRÉATION D'UN OPÉRA}

La commande et la création d'un opéra sont toutes deux conditionnées par des éléments tels que les décisions des directeurs artistiques, les choix des dirigeants d'organismes, les désirs et l'inspiration des compositeurs, l'encadrement institutionnel, la situation financière de l'organisme, les subventions reçues et l'environnement culturel.

Si l'on s'attarde en premier aux directeurs artistiques (de compagnies lyriques ou de maisons d'opéra), force est de constater l'important pouvoir qu'ils détiennent sur la sélection du répertoire présenté au public. Cette autorité se reflète dans la programmation régulière et dans celle des activités hors saison, s'il y a lieu. Comme ce pouvoir émane surtout d'une vision personnelle, le répertoire que les directeurs affectionnent particulièrement se retrouve indéniablement au programme comme le confirme les propos de Bernard Labadie lorsqu'il affirme que « s'il n'y a pas de volonté de créer de l'opéra, il ne s'en fait pas, point à la ligne » et que «la création ne sest pas faite via le canal qui semblait le plus naturel, qui est celui de l'Opéra de Montréal, tout simplement parce qu'il y avait une direction artistique qui s’y opposait, qui nétait pas intéressée ${ }^{38}$ ». Ces propos démontrent bien que les directeurs artistiques orienteront éventuellement les organismes qu'ils dirigent dans la voie de la création s'ils en ont le désir.

Les dirigeants dorganisme ont un rôle tout aussi important à jouer que les directeurs artistiques. En effet, à défaut de ne pas tous avoir une vocation artistique, les dirigeants assurent tout de même l'évolution du genre de l'opéra et du renouvellement du répertoire simplement par leur connaissance pratique du milieu, un esprit ouvert à la création ou aux nouvelles mises en scène et le désir de relever un défi. Cette ouverture envers la création reste cependant tributaire des contingences liées à léquilibre budgétaire dont ils ont la responsabilité.

Quant aux compositeurs, leur désir de créer des œuvres musicales s’explique de lui-même : c'est le choix de carrière qu'ils ont fait et, évidemment, ils en ont envie. Le défi de l'écriture est l'une des motivations principales, et d'après les propos recueillis, les compositeurs éprouvent une réelle satisfaction à créer un opéra lorsque leur inspiration, issue de diverses sources, se trouve conjuguée à un processus de collaboration, à un désir de mettre en commun les connaissances acquises pour ainsi bâtir un tout avec ces multiples éléments. Guidés par cette inspiration (réelle ou artificielle par l'entremise des laboratoires de composition), ils éprouvent le profond désir de perpétuer une forme d'art, de créer quelque chose de réellement nouveau qui peut prendre la forme d'une ouvre d’art synthétique.

L’environnement culturel qui préside à la création d’opéra est un paramètre extrêmement variable, car il est tributaire non seulement d'une situation politico-géographique, mais aussi de la diversité des populations concernées. La

courriel. Le questionnaire comportait une section de questions spécifiques à la catégorie dans laquelle se rangeait l'interlocuteur et une section générale à laquelle tous devaient répondre. Cette dernière section comprenait les cinq questions mentionnées ci-haut.

38 Propos de Bernard Labadie recueillis le 4 juin 2004. 
volonté du milieu artistique (et culturel d'une façon plus large), c'est-à-dire la somme des souhaits et des efforts provenant des artistes, des mécènes et des amateurs d'art, est un moteur essentiel à la création. Cette mise en commun permet parfois d'amener une ouvre à la scène par d'autres moyens que l'aide financière traditionnelle (partenariats et relations entretenues entre organismes producteurs d'opéra et les organismes culturels, campagne de promotion dans la communauté à travers des cours, expositions et lectures publiques). Au Québec par exemple, lorganisme Chants Libres a été fondé par des intérêts privés, mais survit parce qu'une demande se manifeste au sein même des adeptes des musiques d'aujourd'hui. Cette survie est aussi attribuable au fait qu'il y a un vide à combler pour un public fervent de création. Quant au public des abonnés d'une maison d’opéra, il est généralement peu favorable à la création. Mais une campagne d'information abondante (voire surabondante) l'amènera plus volontiers à assister à l'exécution d'une œuvre contemporaine, permettant par le fait même à lorganisme de prendre quelques risques. Le public joue un rôle essentiel dans le développement du répertoire contemporain. Contrairement aux siècles passés, où souvent, seule une élite déterminait le succès d'une œuvre, nous sommes confrontés aujourd'hui à un public hétérogène, aussi difficile à comprendre quà satisfaire. De plus, l'accessibilité plus grande aux arts a considérablement modifié le développement du goût, modification qui se caractérise par un rétrécissement des connaissances désormais canalisées par le pouvoir des médias et des consortiums de l'industrie culturelle. La distance qui sépare l'œuvre contemporaine du public est, par conséquent, de plus en plus grande. C'est dans ce cadre socio-culturel que les maisons d'opéra font tant d'efforts par l'entremise de programmes déveil et de développement de l'auditoire pour rejoindre un public de plus en plus conservateur.

\section{L'AIDE GOUVERNEMENTALE ET L'ENCADREMENT INSTITUTIONNEL}

Aucun projet d'opéra n’a vu le jour au Canada sans l'aide accordée par les conseils des arts ou par Opera.ca. Il nous semble assez évident que la création au Canada est intimement liée aux subventions reçues. Si l'on ajoute à l'équation que, pour recevoir des subventions, la création doit impérativement être cautionnée par un organisme lyrique ou une maison d'opéra répondant à des critères d'attribution précis, nous pouvons affirmer que, malgré le désir d'indépendance des acteurs du milieu, lencadrement institutionnel semble être le premier moteur de création au Canada.

Cependant, il est important de rappeler que les maisons d'opéra et les compagnies lyriques obtiennent un pourcentage important de leur budget des subventions de fonctionnement (aide annuelle ou pluriannuelle) et que seuls les programmes d'aide offerts par Opera.ca se consacrent véritablement à la création. En général, les sommes reçues au fonctionnement permettent simplement aux organismes de présenter leur saison " régulière » et ne favorisent en aucun cas la création. 


\section{UNE AIDE GOUVERNEMENTALE CONTRAIGNANTE?}

De manière générale, l'aide gouvernementale ne s'accompagne pas de mesures contraignantes. Les politiques récentes, celles qui visent à arrimer l'aide des projets aux producteurs, semblent favoriser plusieurs aspects de la production dopéra au Canada, dont la création. Cependant, même ces développements positifs ont des limites et poussent à une concentration des moyens qui risque de réduire le nombre de projets propres à chaque maison d’opéra.

Il y a cependant deux éléments de contrainte dans les programmes gouvernementaux, soit l'exigence d'une situation financière saine et la nécessité de prouver la valeur artistique de l'opéra. Quoique le critère de la santé financière se justifie pour des raisons évidentes, la création bénéficierait de politiques d’aide plus souples pour les compagnies qui aimeraient s'y aventurer. En effet, certains dirigeants ont exprimé une crainte réelle quant aux répercussions possibles sur les futures subventions en cas de création déficitaire. Les risques liés à la création semblent beaucoup plus difficiles à prendre quauparavant, notamment parce que la notion de rentabilité répond à des exigences économiques et non culturelles.

La deuxième contrainte, plus subjective, mais néanmoins bien ancrée dans les pratiques des organismes de production, concerne la valeur artistique des projets déposés. Les candidats doivent non seulement faire valoir la qualité artistique de leur projet auprès des jurys, mais aussi démontrer la compétence artistique de lensemble des collaborateurs tout en justifiant les sommes requises. Bien que les organismes affirment distribuer les subventions sur le jugement impartial de jurys formés de "pairs ", on peut se demander jusquà quel point certains jurés sont suffisamment au courant des différents enjeux de la création. En outre, le système ne peut faire abstraction de la formation et des orientations esthétiques des membres des jurys, deux paramètres qui contribuent à l'orientation des décisions.

\section{VERS DE NOUVELLES SOURCES D'APPUi À LA CRÉATION}

Le désir de créer de nouveaux opéras est bien présent dans le milieu musical canadien. Cependant, puisque les seules ressources disponibles pour la création proviennent d'un programme du CAC et d'Opera.ca, à moins dêtre une maison d'opéra, les organismes intéressés à créer du répertoire canadien doivent se tourner vers d'autres sources de financement. Pour acquérir cette indépendance par rapport au circuit étatique, les organismes doivent prendre de nombreuses initiatives pour trouver de nouveaux fonds. Il s'agit essentiellement de renforcer la promotion de leurs activités dans les milieux privés susceptibles de les aider, tant auprès du public en général que des mécènes et des compagnies ${ }^{39}$. Cest

$39 \mathrm{Au}$-delà du désir et de l'engagement de la compagnie envers un opéra, l'exemple qui suit démontre bien que les liens entretenus avec la communauté culturelle peuvent être une source d’appui considérable et contribuer au succès de toute présentation. Lors de sa saison 2003-2004, la Vancouver Opera a produit le Threepenny Opera de Kurt Weill. La musique du compositeur a été entendue en concert au Vancouver East Cultural Centre, l'Université de la Colombie-Britannique a donné un cours sur l'opéra (dans un format semblable aux Belles Soirées de l'Université de Montréal), le Vancouver Museum a présenté l'exposition Berlin in the 20s - Art \& Politics, la Vancouver Art Gallery a organisé un sympo- 
d'ailleurs ce que confirment les propos de Ruth Bereson $(2002,179)$ et Graham Vick (Royal Philharmonic Society 2003, 5):

$\mathrm{Au} \mathrm{xx}^{\mathrm{e}}$ siècle, les conseils des arts, les grandes sociétés et les mécènes ont été sollicités afin d'assurer la survie [de l’opéra]; il semble qu’au xxie siècle, le bienfaiteur a de nouveau un rôle important à jouer, du moment que son nom est associé avec la maison [d’opéra] ${ }^{40}$.

L'état actuel de la culture en est une de redevance, car ceux qui donnent des fonds espèrent recevoir quelque chose en retour - de l'influence ${ }^{41}$.

C'est aussi par cette pratique que la COC peut aujourd'hui se féliciter de ses réussites en matière de création d’opéra.

De plus, les propos recueillis indiquent que la mise en commun des ressources, pour des projets de partenariat par exemple, rendrait service à la création, car non seulement la qualité de l'œuvre en serait augmentée, mais elle permettrait de rejoindre un public plus large. De plus, si les grandes compagnies pouvaient se permettrent un cycle de création, comme le souhaitait Richard Bradshaw (Domville 2003, 22) ${ }^{42}$, le public s'y habituerait peu à peu. Ceci fidéliserait le public canadien et développerait une demande que les conseils des arts ne pourraient ignorer, ce qui pourrait se traduire par une augmentation de l'enveloppe budgétaire pour l'opéra ou, du moins, une augmentation des rares sommes allouées pour les créations de ce genre. Il n'est pas utopique de penser que cette possibilité puisse se concrétiser à court ou à moyen terme si l'on prend en considération le désir de créer de nouvelles œuvres, un souhait exprimé autant par les responsables d'ateliers que par les compositeurs, les directeurs artistiques de plusieurs organismes et même une partie non négligeable du public.

La création aujourd'hui est donc, en quelque sorte, " un choix de société ». $\mathrm{Si}$, au Canada, le résultat final désiré est un produit culturel sans concession à l'industrie culturelle, il doit être soutenu par le gouvernement au même titre que ce qui se fait en Europe ${ }^{43}$. Cependant, nous avons la chance, au Canada, de pouvoir envisager une structure d'appui aux arts où le système économique pourrait être adapté (à l'image du régime fiscal des États-Unis) afin de faciliter la

sium, et la Vancouver Public Library a offert des séries de forums publics. La somme de ces événements parallèles a donné une impulsion particulièrement favorable à la réception de l’ouvre de Weill. Il n'est pas surprenant que la présentation de l'opéra ait été un grand succès auprès du public.

40 «. .in the twentieth century the arts councils and great corporations and patrons have been looked upon to secure its continued existence; and it would seem in the 21st century the private patron once more has a significant role to play, as long as his name is associated with the house ».

41 « In a culture of accountability, all of those who give money expect something in return - influence».

42 «Idéalement, je voudrais mettre en place un cycle en trois étapes : un opéra canadien faisant l'objet d'une commande, un opéra en cours de révision et de répétition et un opéra à l'affiche ». "Ideally, I want a three-stage cycle: one Canadian opera being commissioned or considered, one in revision and rehearsal and one in performance ».

43 Nous faisons référence, entre autres, au modèle du Théâtre de la Monnaie de Bruxelles qui obtient un réel succès grâce au soutien entier de l'État fédéral. Il existe une entente entre le Théâtre de la Monnaie et l'État fédéral qui assure son financement pour une période de dix ans, soit de 1999 à 2008. Mentionnons aussi le modèle allemand qui garantit le financement des maisons d'opéra, que la salle soit remplie ou non. 
participation du secteur privé (compagnie, mécène, public). Mais pour qu’une telle éventualité se réalise, il faudrait que le milieu de la création puisse susciter un intérêt artistique chez un public sollicité par des formes d'art aussi diversifiées que nombreuses.

\section{L'OPÉRA : UNE FORME D'EXPRESSION CULTURELLE}

Les propos recueillis auprès de nombreux acteurs du milieu nous permettent de confirmer le principe que la création d'un opéra n'est pas un véhicule fondamental pour l'expression de l'identité artistique nationale (canadienne), principalement parce que les pratiques musicales diffèrent selon les attentes culturelles et politiques des divers groupes actifs dans le milieu culturel. Le multiculturalisme du Canada rend pratiquement impossible une définition stable de l'identité nationale. Par ailleurs, la création artistique joue, entre autres, un rôle de différenciation, par exemple, en ce qui concerne l'origine culturelle (pays, province, langue), l'origine ethnique (appartenance à un groupe culturel, à une religion), la classe sociale, le genre et lâge des individus. La création d'un opéra, dans la situation actuelle, comporte peu déléments identitaires nationaux. L'opéra contemporain est tout simplement une forme d'expression culturelle fondamentale. Il fait partie des symboles d'une culture qui dépasse les frontières nationales et qui prend en compte les éléments culturels nécessaires à chaque projet sans nécessairement se soucier du message national. Labolition des frontières nationales est d’ailleurs l'idée directrice des propos de José Evangelista lorsqu'il affirme que : «Même quand on va entendre des opéras [écrits] par des compositeurs allemands ou français, les frontières par rapport au passé, à l'héritage respectif, se perdent. [C'est] encore plus [le cas] dans d'autres cultures qui ne sont pas les cultures dominantes musicalement ${ }^{44}$.»

Lopéra contemporain prend sa source dans de multiples sphères culturelles (musique, littérature, actualité, thèmes à caractère international) et il peut avoir des buts variés : explorer l'univers musical, élargir les techniques associées au multimédia, raconter une histoire québécoise, canadienne ou internationale ou tout simplement tendre vers l'utopie d'une œuvre d'art synthèse ${ }^{45}$. Dans ce dernier cas, ce sont les compositeurs qui y aspirent, car ils voient dans la création d'un opéra la possibilité ultime de satisfaire leur désir de fondre ensemble tou-

44 En réponse à la question : Est-ce que la création d'un opéra est un élément fondamental pour une identité musicale nationale? « Je pense que ça a déjà été vrai, mais ce ne l'est plus ... Je crois que c’est parce que ce n'est plus dans l'air. Même quand on va entendre des opéras [écrits] par des compositeurs allemands ou français, les frontières par rapport au passé, à l'héritage respectif, se perdent. [C’est] encore plus [le cas] dans d'autres cultures qui ne sont pas les cultures dominantes musicalement. » Propos de José Evangelista recueillis le 21 janvier 2004.

45 «Pour moi, c'est le défi »- Ka Nin Chan; " Pour un compositeur, lopéra est la forme ultime " - John Estacio; « Je nétais pas prêt à écrire un opéra il y a dix ans. Je pense qu'il faut développer son métier ainsi que ses habiletés afin de mériter le droit décrire un opéra » - John Estacio; «Lopéra est une pratique très spécialisée. Tout le monde n'est pas intéressé à écrire ou à créer un opéra et ceux qui lont expérimenté une fois ne sont pas nécessairement intéressés à le faire une seconde fois. Je pense que c'est quelque chose avec laquelle il faut être en harmonie ou pas : soit que l'on relève le défi ou pas " - Gary Kulesha. Propos recueillis en entrevue : Chan le 11 février 2004, Estacio le 3 mars 2004, et Kulesha le 24 février 2004). 
tes les disciplines artistiques. Quant aux maisons d'opéra traditionnelles, elles semblent percevoir l'opéra comme un art qui se doit de rester stable en raison des habitudes de programmations limitées au répertoire classique. Les membres des conseils d'administration des différents organismes s'appuyant sur les décisions rendues par les jurys de pairs reconnaissent la valeur de l'opéra en fonction des sommes considérables qui sont attribuées au fonctionnement des maisons d’opéra. Mais le manque de fonds spécifiques pour la création laisse voir qu'ils perçoivent aussi l'opéra comme un art du statu quo, ou encore comme un art dont le développement doit passer par l'autonomie financière.

\section{CoNCLUSION}

Notre étude permet de constater que la plupart des éléments nécessaires à la création d'opéra au Canada sont en place : le désir de créer, des chanteurs bien formés, un auditoire régulier, un nouveau public en croissance et des subventions raisonnablement accessibles et relativement substantielles. De plus, il existe au Canada une vingtaine d'organismes producteurs d'opéras qui assurent la diffusion pour les nouvelles mises en scène et la création d’œuvres nouvelles (voir l'Annexe 2).

Cependant, même si le monde de l'opéra a affiché un plus grand nombre de créations depuis environ une vingtaine d'années quauparavant, le nombre reste globalement peu élevé ${ }^{46}$. Pour des raisons qui touchent à la rentabilité économique et aux choix esthétiques de leurs directeurs artistiques, les maisons dopéra des grands centres urbains se concentrent presque exclusivement sur la production du répertoire traditionnel, tandis qu'un nombre non négligeable de petites compagnies présentent des œuvres aux tendances expérimentales.

La création d'opéra contemporain se heurte aussi à la frilosité du grand public et, par conséquent, à la rareté des reprises. La mesure du succès d'un opéra sévalue par des indices tels que l'importance de l'audience le soir de la première, le ton de la critique du lendemain, et le taux d'affluence des représentations subséquentes (un succès dépasse les $90 \%$ ). Mais la performance d'une création dopéra selon ces critères est rarement positive, et ce genre d'événement artistique ne bénéficie pas d'un modèle de production qui lui assure une place équivalente dans le portrait général de la culture (James 1996, 18) ${ }^{47}$.

De plus, un succès de première ne signifie pas l'assurance de reprises ultérieures. Il est évidemment difficile de juger de l'impact ou de la validité d'une œuvre sur l'écoute de sa simple première, et si l'on se fie à l'histoire, il suffit de penser à Carmen de Bizet ou à Lulu de Berg pour constater que la place historique d'une œuvre ne pourra être déterminée que bien plus tard. Il est vrai qu’on rejoue Harry Somers et John Beckwith à l'occasion en Ontario, et que les œuvres

46 La recension compte environ 95 compositions de 1980 à 1999.

47 «... nowadays, when the house lights go down for a new opera, the audience is in all likelihood unacquainted with the composer, and tonight's piece may well be this first work in the medium. The opera will have been commissioned (or co-commissioned) by the house; it wouldn't have been composed otherwise. The librettist is more likely to be a music critic than a dramatist. Finally, the audience knows, even before the curtain rises, that the production they are about to see is probably the only one the work will receive». 
de Claude Vivier sont présentées au Québec, ce qui augure peut-être de l'intégration progressive de ces œuvres au répertoire. Ces opéras mieux " acceptés " pourront dans l'avenir assurer des succès relatifs de billetterie. Évidemment, si certaines œuvres ne sont pas rejouées en raison de leur piètre valeur artistique, d'autres aux qualités indéniables devront tout simplement attendre dêtre redécouvertes.

\section{L'OPÉRA EN CRÉATION AU CANADA}

La mise en place d'un système public d'aide a eu un impact considérable sur le milieu artistique au Canada et a contribué au développement d’à peu près tous les domaines artistiques. Pour l'opéra, cette aide a contribué entre autres au soutien de grandes institutions et à lémergence de plusieurs compagnies lyriques, permettant ainsi non seulement la présentation du répertoire traditionnel, mais aussi l'augmentation du nombre d'ouvres de création sous plusieurs formes.

Une des conclusions de notre étude établit que les maisons d’opéra du Canada s'en tiennent au répertoire moins risqué sans pour autant abandonner totalement l'espoir de créer des œuvres du répertoire futur. La création, quant à elle, repose de plus en plus sur les compagnies spécialisées. Dans certaines villes, à Montréal par exemple, la compagnie lyrique a tout simplement remplacé la maison d'opéra comme lieu d'accueil des nouvelles œuvres.

Notons qu'il existe des différences notables entre le Québec et l'Ontario en ce qui concerne le développement du nouveau répertoire. En Ontario, la création est plus présente dans les compagnies lyriques que dans la maison d'opéra, mais il existe cependant un certain équilibre entre elles. En fait, puisque la COC est présente dans lévolution du nouveau répertoire, cela incite les compagnies lyriques à se dépasser avec des concepts originaux et des méthodes innovatrices. Il y a donc une " compétition » saine dans un milieu où il est possible d'établir des comparaisons, donc de faire progresser le genre. Queen of Puddings présente du théâtre musical et de l'opéra canadien innovateur et provocateur tandis que Tapestry New Opera Works monte de l'opéra et du théâtre musical tout en concentrant l'essentiel de ses efforts à la rediffusion des créations récentes. Quant à la Canadian Opera Company, elle prend des risques et se positionne en ce moment comme la maison canadienne ayant commandé et produit le plus grand nombre d'opéras canadiens, soit environ une création aux deux ou trois ans.

Au Québec, le seul véritable moteur de création dans le domaine de l'opéra est la compagnie lyrique Chants Libres, dont le répertoire se concentre essentiellement sur des productions mettant la voix en valeur. La compagnie est suivie, d'assez loin, par des institutions d'enseignement et par l'Opéra de Montréal. Depuis sa fondation en 1990, lorganisme a créé dix ouvres nouvelles, ce qui est tout à son honneur considérant les difficultés entourant le processus de la création. Les institutions d'enseignement sont responsables de trois des quatre autres créations ayant eu lieu à Montréal depuis 1980. La Faculté de musique de l'Université de Montréal, l'Atelier lyrique de l'UQAM et le Conservatoire de musique et d'art dramatique du Québec ont respectivement commandé et présenté 
les œuvres Kopernikus, (Claude Vivier, ${ }^{\star} 1980$ ), Le Prix, (Jacques Hétu, ${ }^{\star} 1993$ ) et Hermione et le temps (Gougeon, ${ }^{\star} 2004$ ). Quant à l'Opéra de Montréal, sa seule création fut Nelligan (André Gagnon, ${ }^{\star} 1990$ ), une œuvre jugée " non opératique " qui a choqué les puristes par son langage musical issu de la tradition populaire. Notons toutefois que, sous la direction de Bernard Labadie, l'OdM a fourni des signes de son désir de nouveauté : au cours de la saison 2002-2003, l'OdM a présenté deux œuvres du $\mathrm{xx}^{\mathrm{e}}$ siècle ${ }^{48}$ fort bien accueillies par le public et, à l'automne 2004, son atelier lyrique participait à la création de L'Arche, une œuvre de la compositrice montréalaise Isabelle Panneton ${ }^{49}$. Dans l'attente d'une nouvelle direction artistique, seul l'avenir nous indiquera si la création y sera plus présente au lieu du répertoire traditionnel.

À ce portrait concentré autour de l'Ontario et du Québec, il faut aussi ajouter le nom de deux maisons qui prennent de plus en plus de place dans le panorama de la création musicale au Canada : la Calgary Opera Association, qui semble avoir la volonté de créer régulièrement de nouvelles œuvres en s'appuyant sur le succès remporté par sa première expérience, lopéra Filumena du compositeur John Estacio (John Estacio, ${ }^{\star} 2003$ ) et la Vancouver Opera, qui obtient de grands succès grâce aux liens qu’elle entretient avec sa communauté.

Quel est l'avenir de la création d’opéra au Canada? Il est loin dêtre compromis, mais il devra trouver de nouvelles voies, notamment celle de l'affranchissement des formes d'aide institutionnalisées. De toute façon, après une période de purgatoire liée à la domination du langage sériel (1960-1980) et aux formes musicales qui excluaient à toute fin pratique le genre, l'opéra est redevenu une forme d'art à la mode partout dans le monde. Le Canada néchappe pas à ce courant; comme le dit si bien Bernard Labadie : "Quand on bloque une rivière, elle finit par se trouver des chemins parallèles ${ }^{50}$ ». Au Canada, l'opéra suit maintenant sa voie, associée à une culture non plus simplement nationale, mais bien internationale; et cela, dans la mesure où les êtres humains se rapprochent dans un monde où les frontières s'estompent.

48 Il s'agit d'Erwartung de Schoenberg et du Château de Barbe-Bleue de Bartók, des œuvres datant tout de même du début du siècle passé, mais perçues comme très innovatrices par le public de l'OdM.

49 Le but de cette énumération ne vise pas à comparer le nombre de créations des différentes institutions, mais bien de faire état de la situation de la création. Cependant, force est de constater que la maison d’opéra a un rattrapage important à effectuer.

50 Propos de Bernard Labadie recueillis le 4 juin 2004. 


$\begin{array}{ll}\text { AOTM } & \text { Aide à l'opéra et au théâtre musical } \\ \text { ALP } & \text { Autumn Leaf Performance } \\ \text { CAC } & \text { Conseil des Arts du Canada } \\ \text { CALQ } & \text { Conseil des arts et des lettres du Québec } \\ \text { CAO } & \text { Conseil des arts de l'Ontario } \\ \text { CAT } & \text { Conseil des arts de Toronto } \\ \text { CAM } & \text { Conseil des arts de Montréal } \\ \text { CL } & \text { Chants Libres } \\ \text { COA } & \text { Calgary Opera Association } \\ \text { COC } & \text { Canadian Opera Company } \\ \text { COMUS } & \text { COMUS Music Theatre of Canada } \\ \text { COTM } & \text { Compagnie d'opéra et théâtre musical } \\ \text { MBO } & \text { Modern Baroque Opera } \\ \text { OdM } & \text { Opéra de Montréal } \\ \text { POV } & \text { Pacific Opera Victoria } \\ \text { QP } & \text { Queen of Puddings } \\ \text { RCCC } & \text { Résidences et commandes de compositions canadiennes } \\ \text { TNOW } & \text { Tapestry New Opera Works } \\ \text { UQAM } & \text { Université du Québec à Montréal } \\ & \text { ABRÉVIATIONS ET SIGLES SPÉCIFIQUES AUX FIGURES } \\ \text { (\$C) } & \text { Dollars canadiens } \\ \text { ÉLECTRO } & \text { Électroacoustique } \\ \text { OPÉRA } & \text { Opéra } \\ \text { TM / DANSE } & \text { Musique de scène (théâtre musical) et danse } \\ \text { CHORALE } & \text { Musique chorale } \\ \text { ORCHESTRE } & \text { Musique pour orchestre } \\ \text { DE CHAMBRE } & \text { Musique de chambre } \\ \text { NOUVELLE } & \text { Musique nouvelle } \\ \text { N/D } & \text { Non-déterminé }\end{array}$


Annexe 1 a) Récipiendaires de subventions octroyées par Opera.ca Saison 2001-2002 à 2003-2004 (\$C)

\section{Collaborations}

\begin{tabular}{|c|c|}
\hline 2001-2002 & Pacific Opera Victoria et Tapestry $(15,000)$, Ryan/MacLennan project \\
\hline 2002-2003 & Soundstreams et Opera Breve $(6,000)$, Airline Icarus \\
\hline 2002-2003 & Tapestry Music et Theatre Group $(10,000)$, Antigone \\
\hline 2002-2003 & Vancouver Opera, CMC et BC Region $(9,000)$, Views of Japan \\
\hline 2003-2004 & Opera Ontario $(7,500)$, Joseph Brant-Thayendanega Project \\
\hline 2003-2004 & TNOW $(10,000)$, Over the Japanese Sea \\
\hline \multicolumn{2}{|r|}{ Développement du repertoire } \\
\hline 2001-2002 & ALP Evergreen et Playwright's Workshop $(40,000)$, How it Storms \\
\hline 2001-2002 & Opera Ontario et Numus $(30,000)$, Screen Test \\
\hline $2002-2003$ & Banff Centre et Calgary Opera (40,000), Filumena \\
\hline $2002-2003$ & Chants Libres $(25,000)$, Alternate Visions \\
\hline $2002-2003$ & Queen of Puddings $(17,591.08)$, The Midnight Garden \\
\hline $2003-2004$ & The Banff Centre et COA $(20,000)$, Frobisher \\
\hline 2003-2004 & Canadian Opera Company $(7,500)$, Inanna's Journey Workshop \\
\hline $2003-2004$ & Chants libres et OdM $(30,000)$, Opéra-Féerie \\
\hline $2003-2004$ & Queen of Puddings $(17,591)$, The Midnight Court \\
\hline $2003-2004$ & Tapestry New Opera Works $(16,000)$, The Shadow \\
\hline $2003-2004$ & Vancouver Opera (25,000), Naomi's Road \\
\hline \multicolumn{2}{|r|}{ Production } \\
\hline 2001-2002 & COA et le Banff Centre for the Arts $(70,000)$, Filumena \\
\hline $2001-2002$ & Chants Libres et Les Coups de Théâtre $(40,000)$, Pacamambo \\
\hline 2001-2002 & Modern Baroque Opera $(20,000), 120$ Songs for the Marquis de Sade \\
\hline $2001-2002$ & Soundstreams \& CCOC $(70,000)$, Midwinters Night \\
\hline $2001-2002$ & QP et Western University's Music Faculty $(70,000)$, Charlotte \\
\hline $2002-2003$ & Modern Baroque Opera $(15,000)$, Max \& Moritz \\
\hline $2002-2003$ & OdM, Les coups de théâtre et le NEM $(80,000)$, L'Arche \\
\hline $2002-2003$ & Soundstreams et Dance theatre David Earle $(47,000)$, Death of Enkidu \\
\hline $2002-2003$ & Tapestry et Du Maurier World Stage $(65,000)$, Facing South \\
\hline 2003-2004 & Chants libres $(50,000)$, Alternate Visions \\
\hline 2003-2004 & Manitoba Opera (43,000), Jason and Hanna \\
\hline $2003-2004$ & Modern Baroque Opera $(25,000)$, Powers of Two \\
\hline $2003-2004$ & Tapestry New Opera Works $(25,000)$, Opera to Go \\
\hline \multicolumn{2}{|r|}{ Documentation } \\
\hline 2001-2002 & Chants Libres $(10,000)$, L'Enfant des Glaces \\
\hline $2002-2003$ & Banff Centre $(13,500)$, Filumena \\
\hline $2002-2003$ & Modern Baroque Opera $(6,500)$, Max \& Moritz \\
\hline $2002-2003$ & Tapestry $(15,000)$, Iron Road \\
\hline
\end{tabular}




\begin{tabular}{||l|l||}
\hline 2003-2004 & Canadian Opera Company $(15,000)$, The Brothers Grimm \\
\hline 2003-2004 & \multicolumn{1}{c||}{ Chants Libres $(17,500)$, Alternate Visions } \\
\hline \multicolumn{2}{|c||}{ Dévpement de l'auditoire } \\
\hline $2002-2003$ & Soundstreams Canada $(25,000)$ SomersFest \\
\hline $2002-2003$ & Tapestry New Opera Works $(20,000)$ Inside Opera \\
\hline
\end{tabular}

Annexe $1 \mathrm{~b}$ )

Tableau des subventions octroyées au Québec pour l'OdM et CL (\$C)

\begin{tabular}{||l|l|l|l|l|l||}
\hline \multicolumn{1}{|c|}{$\begin{array}{c}\text { Année } \\
\text { d'attribution }\end{array}$} & \multicolumn{1}{|c|}{ Conseil } & \multicolumn{1}{c|}{ OdeM } & \multicolumn{1}{c|}{ CL } & & \\
\hline $2003-2004$ & CAM & 150000 & 32000 & & \\
\hline $2002-2003$ & CAM & 150000 & 32000 & & \\
\hline $2001-2002$ & CAM & 150000 & 30000 & & \\
\hline $2000-2001$ & CAM & 150000 & 28000 & & \\
\hline $1999-2000$ & CAM & N/D & N/D & & \\
\hline $1998-1999$ & CAM & N/D & N/D & & \\
\hline $2003-2004$ & CAC & 675000 & 105000 & & \\
\hline $2002-2003$ & CAC & 775000 & 107000 & & \\
\hline $2001-2002$ & CAC & 675000 & 95000 & & \\
\hline $2000-2001$ & CAC & 694000 & 32000 & & \\
\hline $1999-2000$ & CAC & 694000 & 95000 & & \\
\hline $1998-1999$ & CAC & 694000 & 50000 & & \\
\hline $2003-2004$ & CALQ & 1160000 & 132600 & & \\
\hline $2002-2003$ & CALQ & 1160000 & 132000 & & \\
\hline $2001-2002$ & CALQ & 865591 & 90600 & & \\
\hline $2000-2001$ & CALQ & 1125000 & 129600 & & \\
\hline $1999-2000$ & CALQ & 1000000 & 130000 & & \\
\hline $1998-1999$ & CALQ & 1000000 & 100000 & & \\
\hline
\end{tabular}


Annexe 1 c)

Tableau des subventions octroyées en Ontario pour QP, ALP, TNOW et la COC (\$c)

\begin{tabular}{|l|l|l|l|l|l||}
\hline \multicolumn{1}{|c|}{$\begin{array}{c}\text { Année } \\
\text { d'attribution }\end{array}$} & \multicolumn{1}{|c|}{ Conseil } & \multicolumn{1}{|c|}{ QP } & \multicolumn{1}{c|}{ ALP } & \multicolumn{1}{c|}{ TNOW } & \multicolumn{1}{|c|}{ COC1 } \\
\hline $2003-2004$ & CAT & N/D & N/D & N/D & N/D \\
\hline $2002-2003$ & CAT & 17500 & N/D & 32500 & N/D \\
\hline $2001-2002$ & CAT & 17500 & 18300 & 32500 & 861162 \\
\hline $2000-2001$ & CAT & 15000 & 21537 & 32500 & 961162 \\
\hline $1999-2000$ & CAT & 11000 & 21537 & 32500 & 854970 \\
\hline $1998-1999$ & CAT & 11000 & 22670 & 31090 & 854970 \\
\hline $2003-2004$ & CAC & 45000 & N/D & 141000 & 1515000 \\
\hline $2002-2003$ & CAC & 64000 & 6000 & 133500 & 1665000 \\
\hline $2001-2002$ & CAC & 74000 & 72000 & 183500 & 1665000 \\
\hline $2000-2001$ & CAC & 55000 & 20000 & 45000 & 1677000 \\
\hline $1999-2000$ & CAC & 70000 & 83000 & 148000 & 1529000 \\
\hline $1998-1999$ & CAC & 61825 & 85000 & 360000 & 1530000 \\
\hline $2003-2004$ & CAO & 29500 & N/D & 50500 & 976980 \\
\hline $2002-2003$ & CAO & 43000 & 0 & 76000 & 1380580 \\
\hline $2001-2002$ & CAO & 26462 & 15390 & 161800 & 976980 \\
\hline $2000-2001$ & CAO & 20000 & 15390 & 41575 & 976980 \\
\hline $1999-2000$ & CAO & 16200 & 17100 & 36630 & 948521 \\
\hline $1998-1999$ & CAO & 13500 & 18000 & 33300 & 948521 \\
\hline 1 Département des affaires culturelles & & & & \\
\hline
\end{tabular}

Annexe 2

Données statistiques des maisons d’opéra et des organismes lyriques du Canada

Saison 2002-2003

\begin{tabular}{|c|c|c|c|c|c|}
\hline Organisme & Location & Fondation & Abonnés $^{1}$ & $\begin{array}{c}\text { Répertoire } \\
\text { habituel }^{2}\end{array}$ & $\begin{array}{c}\text { Dernière } \\
\text { creation } \\
\text { canadienne }\end{array}$ \\
\hline $\begin{array}{l}\text { Canadian Opera } \\
\text { Company }\end{array}$ & Toronto, ON & 1950 & 14,000 & RT / CR & $\begin{array}{l}\text { 2003, projet } \\
2005\end{array}$ \\
\hline Vancouver Opera & Vancouver, CB & 1959 & 6,500 & RT / RR & $\begin{array}{l}1994, \mathrm{OE} \\
2003\end{array}$ \\
\hline Opera Ontario & Hamilton, ON & 1960 & N/D & RT & Nil \\
\hline $\begin{array}{l}\text { Edmonton Opera } \\
\text { Association }\end{array}$ & Edmonton, $\mathrm{AB}$ & 1963 & 3,100 & RT & Nil \\
\hline $\begin{array}{l}\text { Opera } \\
\text { Saskatchewan }\end{array}$ & Regina, SK & 1969 & $\mathrm{~N} / \mathrm{D}$ & RT & $\mathrm{N} / \mathrm{D}$ \\
\hline $\begin{array}{l}\text { Manitoba Opera } \\
\text { Association }\end{array}$ & Winnipeg, MB & 1969 & 2,261 & RT / PRC & Nil \\
\hline $\begin{array}{l}\text { Calgary Opera } \\
\text { Association }\end{array}$ & Calgary, AB & 1972 & 4,500 & $\mathrm{RT} / \mathrm{CR}$ & $\begin{array}{l}2003 \text {, projet } \\
2005\end{array}$ \\
\hline
\end{tabular}




\begin{tabular}{|c|c|c|c|c|c|}
\hline Opera in Concert & Toronto, ON & 1974 & 154 & $\mathrm{RT} / \mathrm{PRC}$ & Nil \\
\hline $\begin{array}{l}\text { Saskatoon Opera } \\
\text { Association }\end{array}$ & Saskatoon, SK & 1978 & $N / D$ & RT / OE & N/D \\
\hline $\begin{array}{l}\text { Pacific Opera } \\
\text { Victoria }\end{array}$ & Victoria, CB & 1980 & 3,850 & RT & 1999 \\
\hline Opéra de Montréal & Montréal, QC & 1980 & 8,799 & RT & Nil \\
\hline Opéra de Québec & Québec, QC & 1980 & 3,878 & RT & Nil \\
\hline Opera Lyra & Ottawa, ON & 1984 & $N / D$ & RT & OE 2003 \\
\hline Opera Atelier & Toronto, ON & 1992 & Nil & OB & Nil \\
\hline $\begin{array}{l}\text { Tapestry New } \\
\text { Opera Works }\end{array}$ & Toronto, ON & 1985 & Nil & CR & $\begin{array}{l}2003 \text {, projet } \\
2005\end{array}$ \\
\hline $\begin{array}{l}\text { Opera } \\
\text { Mississauga }\end{array}$ & Miss., ON & 1985 & $N / D$ & RT & Nil \\
\hline Chants Libres & Montréal, QC & 1990 & Nil & $\mathrm{CR}$ & 2002 \\
\hline $\begin{array}{l}\text { Autumn Leaf } \\
\text { Performance }\end{array}$ & Toronto, ON & 1992 & Nil & CR / PRC & \\
\hline $\begin{array}{l}\text { Opera New } \\
\text { Brunswick }\end{array}$ & Saint John, NB & 1994 & $N / D$ & RT / C & \\
\hline $\begin{array}{l}\text { Queen of } \\
\text { Puddings }\end{array}$ & Toronto, ON & 1995 & Nil & CR & 1999 \\
\hline $\begin{array}{l}\text { Modern Baroque } \\
\text { Opera }\end{array}$ & Vancouver, CB & 1996 & Nil & $\mathrm{OB} / \mathrm{COB}$ & $\begin{array}{l}\text { 2003, projet } \\
2005\end{array}$ \\
\hline Opera Breve & Vancouver, CB & 1997 & $N / D$ & $\mathrm{CL} / \mathrm{CO} / \mathrm{I}$ & $N / D$ \\
\hline $\begin{array}{l}\text { Royal Opera } \\
\text { Canada }\end{array}$ & Miss., ON & 2003 & $N / D$ & RT & Nil \\
\hline \multicolumn{3}{|c|}{$\begin{array}{l}\mathrm{CR}=\text { Création } \\
\mathrm{CO}=\text { Contemporain } \\
\mathrm{COB}=\text { Création d'opéra du genre Baroque } \\
\mathrm{CL}=\text { Classique } \\
\mathrm{I}=\text { Innovateur, } \\
\mathrm{ND}=\text { Non disponible }\end{array}$} & \multicolumn{3}{|c|}{$\begin{array}{l}\mathrm{OB}=\text { Spécialistes de l'opéra Baroque } \\
\mathrm{OE}=\text { Opéra pour enfants } \\
\mathrm{PRC}=\text { Producteur de répertoire canadien } \\
\mathrm{RR}=\text { répertoire récent } \\
\mathrm{RT}=\text { répertoire traditionnel }\end{array}$} \\
\hline \multicolumn{6}{|c|}{$\begin{array}{l}1 \text { Plusieurs compagnies ne maintiennent pas de listes d'abonnés annuelles soit parce qu'elles ne } \\
\text { présentent qu'une seule production par année ou parce que les créations sont souvent sporadiques. } \\
\text { Les données pour ce tableau font référence à la saison 2002-2003. } \\
2 \text { Veuillez noter que ces termes sont employés par les organismes pour décrire leurs activités. Il est } \\
\text { fort possible qu'ils soient interchangeables dans certains cas. Par exemple, le répertoire récent (RR), le } \\
\text { répertoire innovateur (I) et le répertoire contemporain (CO) pourraient tous se trouver sous la bannière } \\
\text { de répertoire contemporain, tandis que classique (C) et répertoire traditionnel (RT) pourraient tous deux } \\
\text { faire référence au répertoire habituel des maisons d'opéra. }\end{array}$} \\
\hline
\end{tabular}


Annexe 3 a)

Pourcentage des aides reçues par la COC, l'OdM et la COA

\begin{tabular}{|c|c|c|c|c|c|}
\hline $\operatorname{coc}^{1}$ & Guichets & Gouv. & Collectes & Autre & COF $^{2}$ \\
\hline 2002-2003 & $39 \%$ & $26 \%$ & $31 \%$ & $4 \%$ & - \\
\hline 2001-2002 & $34 \%$ & $27 \%$ & $35 \%$ & $4 \%$ & - \\
\hline 2000-2001 & $34 \%$ & $24 \%$ & $37 \%$ & $5 \%$ & - \\
\hline 1999-2000 & $38 \%$ & $23 \%$ & $33 \%$ & $5 \%$ & $1 \%$ \\
\hline 1997-1998 & $33 \%$ & $25 \%$ & $32 \%$ & $7 \%$ & $3 \%$ \\
\hline $\mathrm{OdM}^{3}$ & Guichets & Gouv. & Collectes & Autre & \\
\hline 2000-2001 & $45 \%$ & $27 \%$ & $12 \%$ & $16 \%$ & \\
\hline COA & Guichets & Gouv. & Collectes & & \\
\hline 2002-2003 & $46 \%$ & $27,1 \%$ & $26 \%$ & & \\
\hline \multicolumn{6}{|c|}{$\begin{array}{l}1 \text { Compilé à partir des rapports annuels de la COC pour les saisons } 1997 \text { à } 2002 . \\
2 \text { Canadian Opera Fund (fond privé de la COC). }\end{array}$} \\
\hline
\end{tabular}

Annexe 3 b)

Pourcentage des aides reçues par CL, ALP, TNOW et QP

\begin{tabular}{|c|c|c|c|c|c|c|}
\hline \multicolumn{7}{|c|}{$\mathrm{CL}^{4} 2002-2003$} \\
\hline Gouv. féd. & $\begin{array}{c}\text { Gouv. } \\
\text { pro. }\end{array}$ & $\begin{array}{l}\text { Gouv. } \\
\text { mun. }\end{array}$ & Opera.ca & Collecte & $\begin{array}{l}\text { Dons } \\
\text { Autre }\end{array}$ & \\
\hline $27.6 \%$ & $36.8 \%$ & $6.9 \%$ & $11.5 \%$ & $13.8 \%$ & $\begin{array}{l}1.1 \% 2.3 \\
\%\end{array}$ & \\
\hline \multicolumn{7}{|c|}{ Autumn Leaf Performance ${ }^{5}$ 2001-2002 } \\
\hline Gouv. féd. & $\begin{array}{c}\text { Gouv. } \\
\text { pro. }\end{array}$ & $\begin{array}{l}\text { Gouv. } \\
\text { mun. }\end{array}$ & Opera.ca & Collecte & Dons & Guichet \\
\hline $20 \%$ & $5 \%$ & $10 \%$ & $10 \%$ & $10 \%$ & $20 \%$ & $25 \%$ \\
\hline \multicolumn{7}{|c|}{ Tapestry New Opera Works ${ }^{6} 2002-2003$} \\
\hline Gouv. & Collectes & Autre & Guichet & & & \\
\hline $40 \%$ & $20 \%$ & $40 \%$ & $\begin{array}{l}\text { non dis- } \\
\text { ponible }^{7}\end{array}$ & & & \\
\hline \multicolumn{7}{|c|}{ Queen of Puddings ${ }^{5} 2002-2003$} \\
\hline Gouv. & Collectes & Dons & Guichet & & & \\
\hline $66 \%$ & Nil & Nil & $33 \%$ & & & \\
\hline $\begin{array}{ll}1 & \text { Information } \\
2 & \text { Information } \\
3 & \text { Information } \\
4 & \text { Les saisons } \\
5 & \text { Information }\end{array}$ & $\begin{array}{l}\text { eillie auprès } \\
\text { eillie auprès } \\
\text { eillie auprès } \\
\text { irrégulières } \\
\text { eillie auprès }\end{array}$ & $\begin{array}{l}\text { Louise Du } \\
\text { Thom Sol } \\
\text { Anna Can } \\
\text { les produc } \\
\text { Dáirine N }\end{array}$ & $\begin{array}{l}\text { s le } 11 \text { noven } \\
\text { ski le } 23 \text { févr } \\
\text { a le } 11 \text { noven } \\
\text { ns ne sont pa } \\
\text { headhra en s }\end{array}$ & $\begin{array}{l}\text { ore } 2003 . \\
\text { ar } 2004 . \\
\text { ore } 2003 \text {. } \\
\text { rattachées } \\
\text { ptembre } 200\end{array}$ & an endroit $\mathrm{e}$ & articulier. \\
\hline
\end{tabular}




\section{BIBLIOGRAPHIE}

[s.n.] 1997. "A Flight at the Opera Ms McIntosh's Exit Leaves a Crisis at the Garden ». The Guardian, (Manchester, UK), n 15 (May) : 1,20:1.

[s.n.] 2001. « Building Bridges in Iron Road ». The Globe and Mail, (April 19) : 11.

Amiel, Barbara. 2003. «A Measure of Greatness ». Maclean's 116, $n^{\circ} 23$ (June 9) : 58 .

Barrière, Mireille. 2002. L'Opéra français de Montréal : létonnante histoire d'un succès éphémère, 1893-1896. Québec : Fides.

Bereson, Ruth. 2002. The Operatic State-Cultural Policy and the Opera House. New York : Routledge.

Bisson, Sophie. 1998. "Twentieth-Century Canadian Operas Written by Canadian Born or Naturalised Citizens and Landed Immigrants ». Texte inédit (travail de baccalauréat, sous la direction du Dr. John Burge, Queen’s University).

Bissonnette, Lise. 2001. «Ruptures ». Circuit : Ruptures ? 7, n 1 : 13-15.

Botstein, Leon. 1994. «The Opera Revival ». The Musical Quarterly 78, $\mathrm{n}^{\circ} 1$, (Spring) : 1-8.

Chan, Wah Keung. 2003. "Bernard Labadie. Une ère nouvelle à l'Opéra de Montréal ». La Scena Musicale 9, nº 2 (octobre) : 16-18.

Cohen-Levinas, Danielle. 1994. Le présent de l'opéra au $x x^{\mathrm{e}}$ siècle. Chemin vers les nouvelles utopies: pour une esthétique du palimpseste. France: Art edition.

Commanday, Robert. 1987. "The Vanishing of Grand Opera ». San Francisco Chronicle, Sunday Edition, (June 14): 17 et suiv.

Cooper, Dorith R. 1985. « Opera In Montreal and Toronto: A Study of Performing Traditions and Repertoire 1783-1980 ». Thèse de Ph.D., University of Toronto.

Couillard, Claude et Gilles MARCHILDON. 1995. «Québec Artists : From Depression to Conquest ». Performing Arts \& Entertainment in Canada 29, $\mathrm{n}^{\circ} 1$ (Winter) : 8-9.

Crory, Neil. 1996. «Crossover Art : If Opera Only Appeals to a Few, Why Does it Keep Turning up in Popular Culture? ». Opéra C 37, n 4 (Winter) : 18-21.

Denut, Eric. 2002. "Orphée ressuscité? Un panorama de l’opéra contemporain en Europe ». Circuit: Opéra Aujourd'hui 12, n 2:9-19.

Domville, Eric. 2003. "Canadian Themes and Variations». Opera Canada 44, $\mathrm{n}^{\circ} 1$, (Spring) : 18 et suiv. . 2003. « Canadian Overtures ». Opera Canada 43, nº 4 (Winter) : 22 et suiv.

Duchesneau, Michel. 2002. "Avant-propos ». Circuit: Opéra Aujourd'hui 12, $n^{\circ} 2: 7-9$.

Evertt-Green, Robert. 2001. "Opera's New Track ». The Globe and Mail, (April 19), R1 \& R9.

Fortier, André et D. Paul Schafer. 1989. Historique des politiques fédérales dans le domaine des arts au Canada (1944-1988). Ottawa: La Conférence canadienne des arts. 
Foucher, Michel., dir. 1996. Les ouvertures de l’opéra: Une nouvelle géographie culturelle? Collection Transversales. France: Presses universitaires de Lyon. Galaise, Sophie et Johanne Rivest. 1990. " Compositeur québécois. Chronique d’une décennie (1980-1990) ». Postmodernisme 1, nº 1: 83-97.

Green, Judith. 1999. "A Better 'View' of American Opera». The Atlanta Journal the Atlanta Constitution, Home Edition, (October 31) : L16.

Higgins, Charlotte. 2001. " Arts: Why is Opera so Expensive? How can you Charge Audiences up to $£ 155$ a Head and not Make a Profit? ». The Guardian (Manchester, UK), (November 29) : 12 et suiv.

Huss, Christophe. 2004. «Lactualité au secours de l'opéra ». Le Devoir, Édition Internet du samedi 21 et du dimanche 22 août.

James, Jamie. 1996. « American Opera Today: A Gloomy Scenario». Opera News $61, \mathrm{n}^{\circ} 3$ (September) : 18.

Jenkins, Jennifer Rebecca. 2003. «Who Will Buy?: An Examination of Historical and Contemporary Practices of Operatic Patronage in Twentieth-Century America. » Thèse de Ph.D., Northwestern University.

Kallmann, Helmut, James B. Mc Pherson et Gilles Potvin. 1993. «Opéra ». Dans l'Encyclopédie de la musique au Canada, $2^{\mathrm{e}}$ éd., sous la direction de Helmut Kallmann et Gilles Potvin, 2454-2461. Québec: Fides.

Kaptainis, Arthur. 2003. "Quiet Revolution : Bernard Labadie Readies to Set the Tone and Pace for L'Opéra de Montréal ». Opera Canada XLIV, n 3 (Fall) : 22-25.

Kay, Graeme. 2000. «Championship Seasons». Opera News 65, n³ 3 (September): $56-61$.

Kerner, Leighton. 1997. «We Have Seen Opera’s Future». The Village Voice 42, $\mathrm{n}^{\circ} 14$ (April 8) : 74 et suiv.

Kirch, Mai. 2003. "Building a Season: Artistic Visions Meets Bottom Line ». Arias. (Toronto : Canadian Opera Volunteer Committee) : 34, 36 et 77.

Lamb, Gregory M. 2002. "Taking Opera for a Spin; American Operas Are Bursting with Activity and Attracting Crowds, but Is it Enough to Turn Them Into Tomorrow's Classics? ». The Christian Science Monitor (November 1) : 13 et suiv.

MacFarlane, David. 2003. "'Hole in the Ground' Brimming with Potential ». The Globe and Mail (October 15) : A12.

McGregor, Nancy. 1993. "CBC Opera Company ». Dans l'Encyclopédie de la musique au Canada, $2^{\mathrm{e}}$ éd., sous la direction de Helmut Kallmann et Gilles Potvin, 532-533. Québec : Fides.

Morey, Carl et Christopher Morris. 1993. "Canadian Opera Company ». Dans l'Encyclopédie de la musique au Canada, $2^{\mathrm{e}}$ éd., sous la direction de Helmut Kallmann et Gilles Potvin, 197-201, 499. Québec : Fides.

Nattiez, Jean-Jacques. 1992. "Chanter, jouer: l'aventure de Chants libres ». Circuit: Opéra? Gauvreau, Provost, Kagel 3, n 2 : 65-68.

Olivier, Philippe., dir. 1990. Opera : La diva et le souffleur. Série "Mutations ", $\mathrm{n}^{\circ} 71$. Paris : Éditions Autrement. 
Parney, Lisa Leigh. 1997. "The Young: No Longer Phantoms of the Opera Among Twenty-Somethings, Opera is Slowly Shedding its Image as a Stuffy, Elitist Art Form ». The Christian Science Monitor, (February 4) : 10:1.

Perron, Marianne. 1994. "Étude sur le théâtre musical québécois écrit depuis 1968 suivi du répertoire des œuvres ». Mémoire de maîtrise, Université de Montréal.

Poizat, Michel. 1986. L'Opéra, ou, Le cri de l'ange : essai sur la jouissance de l'amateur d’opéra. Paris : A.M. Métailié.

Potvin, Gilles. « Opera de Montréal ». 1993. Dans l'Encyclopédie de la musique au Canada, $2^{\mathrm{e}}$ éd., sous la direction de Helmut Kallmann et Gilles Potvin, 2449-2451. Québec : Fides.

Ramaut-Chevassus, Béatrice., dir. 2003. Composer un opéra aujourd'hui. France : Publications de l'Université de Saint-Étienne.

Rochon, Lisa. 2002. "Will opera house do its civic duty? ". Globe and Mail, (July 3) : R6.

Salzman, Eric. 1999. « Music-Theatre Defined: It's . . Well . . U Um ...». The New York Times, Late Edition, (November 28) : Section 2, Page 7, Column 1.

Smoje, Dujka. 2001. "Les crises du modernisme dans l'histoire musicale ». Circuit: Ruptures? 7, $\mathrm{n}^{\circ} 1: 83-91$.

Stuart, Ross. 1993. "Théâtre musical après 1978 ». Dans l'Encyclopédie de la musique au Canada, $2^{\mathrm{e}}$ éd., sous la direction de Helmut Kallmann et Gilles Potvin, 3242-3248. Québec : Fides.

Thomas, Suzanne et Michelle Quintal. 1993. «Université du Québec à Montréal: Atelier d’opéra ". Dans l'Encyclopédie de la Musique au Canada, $2^{\mathrm{e}}$ éd., sous la direction de Helmut Kallmann et Gilles Potvin, 3408-3409. Québec : Fides.

Tucker, Marilyn. 1986. «The Opera Scene in Europe ». San Francisco Chronicle, Sunday Edition, (December 7) : 16 et suiv.

Vaillancourt, Lorraine. 2001. "Points de départ». Circuit : Ruptures ? 7, $\mathrm{n}^{\circ} 1$ : 9-11.

\section{COMMUNICATIONS, ENTRETIENS ET DOCUMENTS REÇUS}

Entrevues :

Ka Nin Chan (compositeur) : le 11 février 2004

John Estacio (compositeur) : le 3 mars 2004

José Evangelista (compositeur) : le 21 janvier 2004

Sophie Galaise (anciennement directrice au CALQ - musique) : 17 décembre 2003

Sandra Gavinchuk (Canadian Opera Company Ensemble Studio) : 26 février 2004

Denis Gougeon (compositeur) : le 19 mars 2004

Robert Hyland (Conseil des arts et des lettres du Québec) : 9 octobre 2003

Gary Kulesha (compositeur) : le 24 février 2004

France Malouin (Conseil des arts de Montréal) : 15 octobre 2003 
Thom Sokoloski, (Autumn Leaf Performance) : 23 février 2004

Pauline Vaillancourt (Chants Libres) : 10 octobre 2003

Entrevues et conversations téléphoniques :

Wayne Gooding (Opera Canada Magazine) : 13 février 2004 (nombre d’abonnés)

Hélène Haag (Opéra de Québec) : 12 février 2004 (nombre d’abonnés et productions)

Bernadette Hammond (Opéra de Montréal) : 12 février 2004 (nombre d’abonnés)

Bernadette Hammond (Opéra de Montréal) : 19 août 2004 (opéra Hiver dans l'âme)

André Jutras (Conseil des Arts du Canada) : 7 octobre 2003

Bernard Labadie (Opéra de Montréal) : 4 juin 2004

Chantal Lambert (Atelier lyrique de l'Opéra de Montréal) : 4 mai 2004

Rosemarie Landry (Atelier d’opéra de l'Université de Montréal) : 15 octobre 2003

Andrew Lee (Conseil des arts de Toronto - Division culturelle) : 2 novembre 2003

Ramon Maskkayan (Opera in Concert) : (Date de fondation et nombre d'abonnés)

Micheline McKay (Opera.ca) : 19 décembre 2003

Bob McPhee (Calgary Opera Association) : 12 novembre 2003

Dixie Sing Neill (McGill Opera Studio) : 2 octobre 2003

Anja Nopper (Opéra de Montréal) : mai et juin 2004 (données financières)

Joanna Slobodian (Manitoba Opera Association) : avril 2004 (abonnés \& productions)

Documents reçus par courriel ou par la poste :

Canadian Opera Company (Lisa Barty)

- Programme Composer in Residence

- Demandes de subventions au programme Résidence du CAC

- Créations de la COC

Canadian Opera Company (Jennifer Pugsley)

- Rapports annuels 1997-1998 à 2001-2002

- Something to sing about, School Programs 2003 / 2004

- Adventures in Opera!, Programs for young people

- Please join us, Appel de contribution

- Up and Coming, Lectures for the 2003-2004 season

- Get ready for the Ring!, Adult programs 2003-2004

- After School Opera Program 2003/2004

Chants Libres (Louise Dugas) : Données financières

Conseil des arts de Montréal (France Malouin)

- Subventions reçues par Chants Libres de 1981 à 2003

- Subventions reçues par l'Opéra de Montréal de 1981 à 2003 
Conseil des arts de l'Ontario

- Rapport annuel 1997-1998 à 2001-2002

- Guide des subventions

- Commande d'œuvres musicales

Conseil des arts et des lettres du Québec (Robert Hyland): Les organismes de production en musique subventionnés par le Conseil des arts et des lettres du Québec de 1994-1995 à 1997-1998. Portrait économique. Document émis par le CALQ en octobre 2002.

McGill Opera Studio (Dixie Sing Neill): Chronologie des productions d'opéras présentés par la faculté.

Modern Baroque Opera (Kate Hutchinson)

- Subventions reçues

- Créations de nouveaux opéras

Opera.ca (Micheline McKay) : Rapports annuels pour les années d'attribution de 2001 à 2004

Opéra de Montréal (Anja Nopper) : Dossier de presse de l'OdM

Pacific Opera Victoria (David Devan)

- Subventions reçues

- Nombre d'abonnés

Queen of Puddings (Dáirine Ní Mheadhra) : Subventions reçues

Royal Philharmonic Society (Graham Vick) : Transcription de la présentation

Inclusion or be damned, donnée par Graham Vick dans le cadre des Royal

Philharmonic Society Lecture à Londres, en Angleterre, le 18 octobre 2003.

Tapestry New Opera works (Anna Camara) : Subventions reçues

\section{WEBOGRAPHIE}

Autumn Leaf Performance : Fonctionnement général de lorganisme, <http:// www.autumnleaf.com>

Canadian Opera Company (The) :

- Histoire de la COC / Communiqués de presse, <http://www.coc.ca>

- Informations générales sur la production Der Ring des Nibelung et sur le Four Seasons Centre, <http://www.fourseasonscentre.ca (FAQ) \& $<$ http://www.ringcycle.ca $>$

- 2000 Sommes accordées à la COC par le département des affaires culturelles de la ville de Toronto / 2000 : June 192000 / section 7.6, p.9, $<$ http://www.city.toronto.on.ca/legdocs/2000/minutes/committees/ed/ ed000619.pdf $>$

- 2001 Sommes accordées à la COC par le département des affaires culturelles de la ville de Toronto / 2001 : June 112001 / section 7.4, p.7, $<$ http://www.city.toronto.on.ca/legdocs/2001/minutes/committees/edp/ edp010611.pdf>

- 2002 Sommes accordées à la COC par le département des affaires culturelles de la ville de Toronto / 2002 : May 292002 / section 5.7, p.11, 
$<$ http://www.city.toronto.on.ca/legdocs/2002/minutes/committees/edp/ edp020529.pdf>

- 2003 Sommes accordées à la COC par le département des affaires culturelles de la ville de Toronto /2003 : May 52003 / section 3.10, p.21, $<$ http://www.city.toronto.on.ca/legdocs/2003/minutes/committees/edp/ edp030505.pdf>

Chants Libres :

- Fondation de lorganisme et répertoire, <http://www.chantslibres.org> Conseil des arts de Montréal :

- Fondation du conseil des arts et programmes d'aide, <http://www.artsmontreal.org>

Conseil des arts de l'Ontario :

- Fondation du conseil des arts et programmes d'aide, <http://www.arts. on.ca>

- 2003 Rapport annuel et liste des subventions 2002-2003 (p.vi \& p. 31), $<$ http://www.arts.on.ca/Asset841.aspx?method=1>

- 2004 Le CAO en bref, <http://www.arts.on.ca/Page677.aspx>

- $\quad<$ http://www.toronto.ca/legdocs/minutes.htm> (1998-2005 minutes)

Conseil des arts de Toronto (incluant : City of Toronto - COC)

- 1999-2003 Grant Allocations 1999-2003

- Minutes of the Economic Development and Parks Committee <http:// www.toronto.ca/legdocs/minutes.htm> (1998-2005 minutes) <http:// www.torontoartscouncil.org/grant-allocations.htm>

- 1999-2000 Profile of Funding to Artists and Arts Organizations in the City of Toronto, 1999-2000 <http://dsp-psd.communication.gc.ca/ Collection/K21-23-2000E.pdf >

- CAT / City, 1999-2003

- Minutes of the Economic Development and Parks Committee / 19982003 Minutes;

- 2000 : June 192000 / section 7.6-(consulté le 24 août 2004)<http://www. city.toronto.on.ca/legdocs/2000/minutes/committees/ed/ed000619.pdf>;

- 2001 : June 112001 / section 7.4-(consulté le 24 août 2004) <http://www. city.toronto.on.ca/legdocs/2001/minutes/committees/edp/edp010611. pdf $>$;

- 2002 : May 292002 / section 5.7 - (consulté le 24 août 2004) <http://www. city.toronto.on.ca/legdocs/2002/minutes/committees/edp/edp020529. pdf $>$;

- 2003 : May 52003 / section 3.10 - (consulté le 24 août 2004) <http://www. city.toronto.on.ca/legdocs/2003/minutes/committees/edp/edp030505. pdf $>$.

Conseil des arts et des lettres du Québec:

- Communiqués, fondation du conseil des arts et programmes d'aides, www. calq.gouv.qc.ca

- 2003.1 Subventions aux organismes artistiques 2002-2003 / musique, <http://www.calq.gouv.qc.ca/publications/rapann_20022003.pdf> 
- 2003.2 Bourses et subventions octroyées, <http://www.calq.gouv.qc.ca/ calq/aide/bourses_subv.htm>

Conseil des Arts du Canada :

- Communiqués, fondation du conseil des arts et programmes d'aides $<\mathrm{http}: / /$ www.conseildesarts.ca $>$ et $<$ http://www.conseildesarts.ca/musique $>$

- Liste interrogeable des subventions, <http://www.conseildesarts.ca/subventions/recipients-fr>

- Rapports annuels 1998-2003, <http://www.canadacouncil.ca/aproposdenous/organisation/rapportsannuels/>

- Subventions du Conseil des Arts du Canada par programme et provincel territoire - Ventilation annuelle 1998-1999 à 2002-2003, <http://www. conseildesarts.ca/publications_f/statistiques/ua127235083629218750. htm>

- Profils de l'aide accordée aux disciplines artistiques 1998-2003<http://www. conseildesarts.ca/publications_f/statistiques/pl127235090956093750. htm>

- RCCC.1 Résidences et commandes de compositions canadiennes, <http:// www.conseildesarts.ca/subventions/musique/kg127245427079218750. $\mathrm{htm}>$

- RCCC.2 Un survol du programme de commandes de compositions canadiennes, <http://www.conseildesarts.ca/subventions/musique/ if $127254088985312500 . \mathrm{htm}>$

- $\quad$ RCCC.3 Liste interrogeable de subventions, <http://www.conseildesarts. $\mathrm{ca} /$ subventions/recipients-fr $>$

- $\quad$ RCCC.4 Liste interrogeable de subventions, <http://www.conseildesarts. ca/subventions/recipients-fr> et Rapports annuels 1998-2003, <http:// www.conseildesarts.ca/aproposdenous/organisation/rapportsannuels/ $>$

- 2003.1 Profils de laide accordée aux provinces et territoires / Aide accordée en 2002-2003 pour le Québec, <http://www.conseildesarts.ca/ publications_f/statistiques/ek127235070467031250.htm>

- 2003.2 Profils de laide accordée aux provinces et territoires / Aide accordée en 2002-2003 pour l'Ontario, <http://www.conseildesarts.ca/ publications_f/statistiques/ek127235070467031250.htm>

- 2003.3 Profils de laide accordée aux provinces et territoires / Aide accordée en 2002-2003 pour le Québec, <http://www.conseildesarts.ca/ publications_f/statistiques/ek127235070467031250.htm>

- 2003.4 Profils de laide accordée aux provinces et territoires / Aide accordée en 2002-2003 pour l'Ontario, <http://www.conseildesarts.ca/ publications_f/statistiques/ek127235070467031250.htm>

- 2004.1 Le Conseil des Arts du Canada injecte 2,5 millions de dollars dans la création d’opéras, $<\mathrm{http}$ //www.canadacouncil.ca/nouvelles/communiques/2001/dw127240981872343750.htm>

Opera.ca :

- Opera.ca 1 Programme de création d’opéras canadiens, <http://www.opera. $\mathrm{ca} / \mathrm{fre} . \mathrm{cfm}>\mathrm{et}$ « Report on Canadian Opera Creation Program Canadian 
Opera Fund 2002 », p. 2. Document obtenu auprès de Micheline McKay d'Opera.ca.

Opera Atelier :

- Informations générales, <http://www.operaatelier.com>

Opéra de Montreal (L') :

- Information Générale : Fondation de l'Opéra de Montréal, historique et communiqués, <http://www.operademontreal.com>

Tapestry New Opera works :

- Fondation de Tapestry New Opera works répertoire, <http://www. tapestrynewopera.com>

Vancouver Opera :

- Fondation de Vancouver Opera et répertoire, <http://www.vanopera. bc.ca>

\section{RÉSUMÉ}

Lanalyse des différents programmes d'aide offerts par les conseils des arts canadiens révèle que l'aide financière gouvernementale est insuffisante pour permettre la création régulière d’ouvres opératiques. Létude du fonctionnement des organismes professionnels qui bénéficient de ces programmes d'aide (incluant les ateliers professionnels et universitaires), ainsi que létude des mécanismes entourant la création d'un opéra (de sa commande à sa réalisation), démontre que l'essentiel des fonds contribue au fonctionnement des différents organismes lyriques du pays et non à la création. Pour permettre la création d'opéra au Canada, les créateurs doivent emprunter le chemin de la compagnie lyrique et non de la maison d’opéra.

\section{ABSTRACT}

Analysis of the various programmes offered by the Canada Council for the Arts reveals that government financial aid is not sufficient to allow for the consistent creation of operatic works. This is further borne out by studies of the operations of various professional organisations that benefit from these programmes (including professional and university workshops), as well as all the mechanisms that surround the premiere of a new opera (from its commissioning to its first staging). In sum, most of the funds are used to meet operating costs of the country's various operatic organisations. In order for Canadian opera to thrive, composers must turn to lyrical companies and not opera houses. 